\title{
Strengthening of Reinforced Concrete Beams using Ultra High Performance Fibre Reinforced Concrete
}

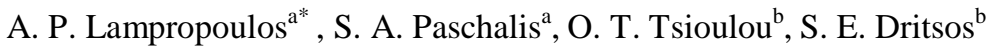 \\ ${ }^{a}$ University of Brighton, Environment and Technology, Moulsecoomb, Brighton, BN2 4GJ, UK \\ * University of Brighton, Environment and Technology, Moulsecoomb, Brighton, BN2 4GJ, UK \\ Tel.: +44 (0) 1273 642306, E-mail address: A.Lampropoulos@ brighton.ac.uk \\ ${ }^{\mathrm{b}}$ Department of Civil Engineering, University of Patras, 265 00, Patras, Greece
}

\begin{abstract}
In this study the efficiency of the use of Ultra High Performance Fibre Reinforced Concrete (UHPFRC) for the strengthening of existing Reinforced Concrete (RC) beams has been investigated. Experimental work has been conducted to determine UHPFRC material properties. Dog-bone shaped specimens have been tested under direct tensile loading, and standard cubes have been tested in compression. These results have been used for the development of a numerical model using Finite Element Method. The reliability of the numerical model has been validated using further experimental results of UHPFRC layers tested under flexural loading. Further numerical study has been conducted on full-scale beams strengthened with UHPFRC layers and jackets, and these results were compared to respective results of beams strengthened with conventional RC layers and with combination of UHPFRC and steel reinforcing bars. Superior performance was observed for strengthened beams with UHPFRC three side jackets, and the efficiency of this technique was highlighted by comparisons with other strengthening techniques.
\end{abstract}

\section{Highlights}

- Experimental investigation was conducted to determine mechanical properties and shrinkage of UHPFRC.

- Numerical model was developed for the simulation of UHPFRC.

- The efficiency of UHPFRC layers and jackets for the strengthening of existing beams was assessed.

- Superior performance was observed in terms of stiffness, yield \& maximum strength, when three side UHPFRC jacket was used.

\section{Keywords}

Ultra High Performance Fibre Reinforced Concrete

Reinforced concrete beams

Strengthening

Layers

Jackets 


\section{Introduction}

A novel technique used to improve the performance of existing structural elements is the application of additional Ultra High Performance Fibre Reinforced Concrete (UHPFRC) layers or jackets in connection to the existing elements. The efficiency of this technique has not been adequately studied, and there are not any published studies on the evaluation of this method with comparisons to other traditional strengthening methods such as the use of Reinforced Concrete (RC) layers and jackets.

The technique of strengthening using additional RC layers and jackets is one of the most commonly used techniques in seismic areas. There are several published experimental and theoretical studies on beams and columns strengthened with conventional concrete [1-15]. A crucial parameter in this technique, which can considerably affect the durability and the performance of the strengthened structures, is the concrete shrinkage strain of the additional layers/jackets. Additional stresses are induced in strengthened elements, and cracking of the new layer and/or de-bonding may occur [8-15]. The use of UHPFRC could potentially improve both durability and resistance due to its superior mechanical properties.

This study is focused on the addition of UHPFRC layers or jackets to existing RC beams. UHPFRC is a novel material with superior strength and energy absorption. There are several published studies on UHPFRC and the mechanical properties of this material have been studied extensively [16-21]. The percentage of the steel fibres is one of the most crucial parameters affecting the flexural strength and the ductility of UHPFRC elements. According to published experimental studies [16, 17], increment of the steel fibres amount, results to an increment of the flexural strength, while the ductility is reduced. The effect of fibres' orientation and distribution in the mix was investigated by Kang \& Kim [18]. According to this study [18], fibres' orientation and distribution has negligible effect in the pre-cracking behaviour while in the post-cracking phase, this considerably affects the material properties. Experimental test methods appropriate for the evaluation of the mechanical properties of UHPFRC were proposed by Hassan et al. [19]. A detailed investigation on the assessment of the performance of UHPFRC was presented by Toledo et al. [20], and the development of the mechanical properties of UHPFRC with the time was extensively studied by Habel et al. [21]. The direct tensile behaviour of UHPFRC was examined by Kang et al. [16], and tri-linear tensile fracture model with softening phase was proposed via an inverse analysis. An inverse finite element analysis method was also proposed by Neocleous et al. [22] for deriving the tensile characteristics of Steel Fibre Reinforced Concrete (SFRC). The effect of fibre distribution on UHPFRC was highlighted in Ferrara et al [23]. In this study the effect of different fibre orientations was examined. For this reason, slabs with the same size but different flowing direction were cast. From these slabs, beam specimens were cut with their axis parallel and perpendicular to the flow direction. From the results it was evident that the orientation of the fibers affects considerably the mechanical performance of fiber reinforced cementitious composites [23].

The findings presented in the previous studies are mostly focused on the mechanical properties of UHPFRC, and there are other published studies on strengthening applications [24-31]. Farhat et al. [24] examined beams strengthened with UHPFRC strips. Epoxy adhesive was used for the bonding between UHPFRC and the initial beam. In this study [24], UHPFRC prevented shear failure of the beams and the failure load was increased up to $86 \%$. Bruhwiller \& Denarie [25] and Brühwiler [26] studied the application of UHPFRC for the rehabilitation of crash barrier wall of highway bridge, bridge pier, and industrial floors, and the efficiency of this method for cast in-situ and prefabrication, using standard equipment for concrete manufacturing, was highlighted. The application of UHPFRC for the repair and strengthening of beam-column joints was investigated by Beschi et al. [29] and remarkable bearing capacity increment was observed [29]. Combination of UHPFRC with reinforcing steel bars for the rehabilitation of existing concrete elements was examined by Habel et al. [27] and this technique was found to be quite promising, since the existing structures were efficiently strengthened and their resistance and their ultimate moment were considerably increased [27]. An analytical model for elements strengthened with combined UHPFRC and steel bars was proposed by Noshiravani and Brühwiler [28] together with a simplified formulation for the shear resistance of the composite members [28]. Magri et al. [30] investigated the combination of UHPFRC with Textile Reinforced Mortar (TRM) and increment of maximum load capacity and ductility of the examined specimens was observed [30].

However, until now, there are not any published studies on three sides jacketing with UHPFRC, and there are not any direct comparisons of the use of UHPFRC layers or jackets with traditional strengthening techniques. The main aim of this paper is to investigate the effectiveness of the addition of 
UHPFRC layers or jackets to RC beams and to conduct a critical comparison of the effectiveness of this novel technique with traditional strengthening methods using RC layers. In this paper, a numerical investigation is presented first (Section 2) on initial, prior to strengthening, RC beams. Experimental work was conducted to determine the actual material characteristics in tension and compression and, using these data, a numerical model was developed for the simulation of UHPFRC. The accuracy of the model was further validated with flexural tests on UHPFRC layers (Section 3). An extensive numerical investigation was conducted on beams strengthened with layers and jackets (Section 4). The performance of these specimens was compared to respective results of elements strengthened with additional RC layers, and the superior performance of beams with three side UHPFRC jacket was highlighted (Section 5).

\section{Reinforced Concrete Beams prior to strengthening: Numerical modelling and experimental validation}

The Initial, prior to strengthening, Beam (IB) examined in this study is based on a previous experimental program [7]. Initial Beam's cross sectional dimensions were $150 \mathrm{~mm}$ by $250 \mathrm{~mm}$ and the length was equal to $2200 \mathrm{~mm}$. The reinforcement consisted of two bars with a diameter of $12 \mathrm{~mm}$ (2H12) made of steel with a characteristic yielding stress value of $500 \mathrm{MPa}$ in the tensile side with a cover of 25 $\mathrm{mm}$ (Fig. 1a). The characteristic cylinder concrete compressive strength of the initial beam at 28 days was found equal to $39.5 \mathrm{MPa}$. The effective span was equal to $2000 \mathrm{~mm}$ and the beam was tested under a fourpoint bending loading with an imposed deflection rate of $0.008 \mathrm{~mm} / \mathrm{sec}$. The distance between the two loading points in the middle of the span was equal to $500 \mathrm{~mm}$.

For the finite element analysis, ATENA software [32] was used. Concrete was simulated with an eight-node element, with nonlinear behaviour and softening branches in both tension and compression using SBETA constitutive model [32]. The ascending compressive branch of this model is based on the formula recommended by CEB-FIP model code 90 [33], while its softening law is linearly descending from the peak stress until a limit compressive strain, which was defined by the plastic displacement and the band size, using the fictitious compression plane model [32] (Fig. 2). In tension, linear ascending branch and exponential softening branch based on the fracture energy needed to create a unit area of a stress free crack were used [32]. In all the analyses smeared crack approach was used [32]. For the simulation of steel bars, linear elements with bilinear behaviour were used. The numerical results $\left(\mathrm{IB}_{\text {num }}\right)$ are compared to the respective experimental for $\left(\mathrm{IB}_{\text {exp }}\right)$ and the results are presented in Fig. 3 [31].

From the results presented in Fig. 3, very good agreement between the numerical and the respective experimental results was observed. The same assumptions were used for the modelling of RC layers and beams presented in the following sections.

\section{Experimental investigation and Numerical Modelling of UHPFRC}

\subsection{UHPFRC material preparation}

UHPFRC is a material with enhanced strength in tension and compression and significantly high energy absorption in the post-cracking region. One of the main characteristics of UHPFRC is the enhanced homogeneity which is achieved by using fine aggregates only. In the mix design of the present study, silica sand with maximum particle size of $500 \mu \mathrm{m}$ was used together with silica fume and Ground Granulated Blast Furnace Slag (GGBS). Silica fume, with particle size almost 100 times smaller than cement, improve not only the density of the matrix but also the rheological properties, while GGBS is used as a partial replacement of cement. High steel fibre content (3\%) of straight fibres with $13 \mathrm{~mm}$ length and $0.16 \mathrm{~mm}$ diameter were used. The mix design is presented in Table 1 and it was based on a previous experimental investigation [19].

For the preparation of UHPFRC the dry ingredients were mixed first for 3 minutes in a high shear mixer Zyklos (Pan Mixer ZZ 75 HE), then the water and the superplasticizer were added to the mix and, at the end, the steel fibres were added gradually. The specimens were cured in a steam curing tank at $90^{\circ} \mathrm{C}$ for 3 days and the testing was conducted 14 days after casting. These curing conditions were found to be appropriate for the acceleration of the curing, since the strength achieved after 3 days in the steam curing tank $\left(90^{\circ} \mathrm{C}\right)$ was the same with the strength achieved 3 months under normal curing conditions. 


\subsection{Compressive and direct tensile tests and numerical modelling}

The standard cube compressive tests ( $100 \mathrm{~mm}$ side) were conducted and the mean compressive strength was found equal to $164 \mathrm{MPa}$ while for the tensile strength, direct tensile tests of 6 dog-bone specimens were carried out (Fig. 4) [34].

A constant loading rate of $0.007 \mathrm{~mm} / \mathrm{sec}$ was used to control the tests which is in agreement with the loading rate used by Hassan et al. [19] leading to comparable results. The extension of the specimens was recorded using Linear Variable Differential Transformers (LVDTs). The setup of Fig. 4b was used to measure the average extension over a gauge length of $105 \mathrm{~mm}$, and the stress versus strain (extension normalized to the gauge length) results of all the 6 specimens together with the average curve are presented in Fig. 5 [34].

The experimental results indicate a variation of the tensile strength between $11.74 \mathrm{MPa}$ and 14.20 MPa. An average stress-strain curve was calculated and the average strength was found equal to $12 \mathrm{MPa}$ (Fig. 5). The Young' s modulus was experimentally obtained from the slope of the initial linear part of the stress-strain graph in the linear part (Fig. 5) and a value of 57.5 GPa was calculated.

The setup used for the optical measurement of the crack together with the strain distribution at the moment when the first crack appeared, are presented in Fig. 6, alongside with stress-strain results for one of the examined specimens [34].

Digital Image Correlation (DIC) system was used during the testing in order to monitor the crack opening and the strain distribution (Fig. 6). According to these results (Fig. 6), the strain is uniformly distributed along the specimen in the elastic part of the stress-strain distribution (strain values below 0.001 ). Then, in the second phase (strain between 0.001 and 0.005 ) there is a combination of micro cracks and elastic strain in the neck of the dog bone specimen and, in this phase, the multiple micro cracks opening was taken into account as an average crack opening along the monitoring length (Fig. 6). For strain values higher than 0.005 , all the extension of the specimen was due to the crack opening (Fig. 6).

Comparisons of the mechanical characteristics of the examined mix with other mix designs from relevant studies in the literature $[19,20,21]$ are presented in Table 2.

From the results of table 2, it can be observed that the addition of GGBS and the increment of the percentage of steel fibers in the mix improve both compressive and tensile strength.

\subsection{Numerical Modelling of UHPFRC}

For the numerical modelling of UHPFRC, finite element software ATENA was used [32]. The material properties adopted in the models were based on the experimental results of compressive and tensile tests (Section 3.2). A compressive strength of $164 \mathrm{MPa}$ and Young's modulus equal to $57.5 \mathrm{GPa}$ were used for the modelling in compression with SBETA constitutive model [32] (Fig. 2). The use of this model with Young's modulus and ultimate compressive strength derived from the experimental tests, leads to an almost linear ascending branch which is in agreement with the experimental results presented by Hassan et al. [19] and Graybeal [35] and with proposed design recommendations [36, 37].

The behaviour in tension was modelled based on the experimental results presented in Fig. 5 and Fig. 6. The behaviour was considered linear up to a tensile strength of $11.5 \mathrm{MPa}$ and, after the end of the elastic part, the stress-strain presented in Fig. 7 was adopted for a characteristic size equal to $2 \mathrm{~mm}$ [31]. This model is in agreement with the model proposed by Habel et al. [27] and adopted by Bruhwiler [26] and Noshiravani and Bruhwiler [28]. According to this model, the behaviour of UHPFRC is modelled with an elastic behaviour up to initiation of the microcracking followed by a second linear part in to the phase of strain hardening with multiple microcracking. Then after the formation of the macrocrack at ultimate resistance there is the strain softening phase which was modelled by a bi-linear model. This is in agreement with the model used in the current study for the modelling of UHPFRC in tension.

The dog-bone specimens were modelled using the properties described above, and the examined numerical models are presented in Fig. 8 [31].

The numerical results were compared to the average of the experimental and the results are presented in Fig. 9 [31].

The results indicate that the numerical model can accurately predict the response of UHPFRC under direct tensile loading. In order to further validate the accuracy of the numerical model, layers with $50 \mathrm{~mm}$ thickness were tested under flexural loading. 


\subsection{Experimental and numerical investigation of UHPFRC layers under flexural loading}

In this section, experimental and numerical results of layers with $50 \mathrm{~mm}$ depth were examined.

During the casting process, the specimens were cast by pouring the material centrally along the long side and filling the first layer up to approximately $90 \%$ of the height of the specimen before the compaction by external vibrator [38]. Afterwards, the moulds were filled and compacted as described in BS EN 14651:2005 [38], and then the specimens were rotated over $90^{\circ}$ around their longitudinal axis for testing [38].

Three identical specimens were tested under 4 point loading, with $100 \mathrm{~mm}$ breadth, span length of $300 \mathrm{~mm}$, and distance between the two loading points $100 \mathrm{~mm}$. Two LVDTs were used to record the deflection of the layers in both sides, and the tests were conducted using a displacement control of 0.001 $\mathrm{mm} / \mathrm{sec}$ [39]. An external yoke (Fig. 10a) was used in order to exclude any additional displacement at the supports. The testing setup is presented in Fig. 10a and a typical crack pattern is illustrated in Fig. 10b [34].

The examined layers were modeled using the assumptions presented in Section 3.3. The numerical model is presented in Fig. 11a, and the strain contours together with the crack pattern at mid-span deflection equal to $10 \mathrm{~mm}$, are presented in Fig. 11b. A deflection equal to $10 \mathrm{~mm}$ was selected as this was the typical mid-span deflection at the end of the tests (Fig. 10b).

The strain localization in the middle of the span observed in the experimental investigation (Fig. 10b) was in agreement with the numerical simulation's results presented in Fig. $11 \mathrm{~b}$.

The load deflection predictions are compared with the respective experimental results of all the three specimens [34] and the results are presented in Fig. 12.

The numerical results are in good agreement with two of the examined layers, while in one of the examined specimens the strength was considerably lower compared to the other two. This could be attributed to local deficiencies due to the fibre distribution in the mix which resulted to a premature failure of the specimen.

The assumptions presented in Section 2 and in Section 3.3, for the initial beam and the UHPFRC layers respectively, were used for the simulation of the strengthened beams with UHPFRC.

\subsection{Experimental investigation of UHPFRC Shrinkage}

In case of strengthened elements with concrete jackets, crucial parameters for the response of these 'composite' elements are the interface between the old and new concrete, and the shrinkage of the 'ne w' concrete [15]. Shrinkage strain measurements were recorded over the time for UHPFRC with 3\% steel fibres and for Ultra High Performance Concrete (UHPC) without fibres. The mix design of Table 1 was used, and standard prisms $75 \mathrm{~mm}$ by $75 \mathrm{~mm}$ by $280 \mathrm{~mm}$ were cast. The specimens were stored in a room with relative humidity $42 \%$ and temperature $20^{\circ} \mathrm{C}$ (Fig. 13a) conditions similar to the standard climate (temperature $23 \pm 2^{\circ} \mathrm{C}$ and relative humidity or RH 50 \pm ) proposed by DIN 50014-23/50-2 [40]. The shrinkage strain distribution with the time is presented in Fig. 13b. As a starting point for these measurements (Day 0 in Fig. 13b), the third day after casting was used, when the initial curing was completed.

The results presented in Fig. 13b indicate that the presence of the steel fibres considerably reduces shrinkage strain values and an average reduction of the shrinkage strain with the time of $30 \%$ was observed. In case of UHPFRC with 3\% steel fibres (Table 1), the shrinkage strain 90 days after casting was measured equal to 565 microstrains. Shrinkage strain values are highly affected by a number of parameters including the mix design, the curing conditions and the geometry of the examined specimens. Yoo et al. [41] used a special setup to simulate the conditions of free UHPFRC shrinkage effects on slabs and a very steep increase of shrinkage at the very early age was observed. Kamen [42] and Kamen et al. [43] conducted measurements on specimens with similar geometry to those of the current study (prisms and dog-bone shaped specimens) and a distribution similar to the one presented in Fig. 13b was observed. Also, according to Kamen et al. [43], in the first 2 days there is a chemical shrinkage state after the watercement contact, followed by a swelling, and the main part of shrinkage strain is developed after the first two days. 


\section{Numerical modelling of strengthened beams with UHPFRC}

In this section, the numerical investigation on beams strengthened with additional layers and jackets is presented. The Initial Beam (IB) was identical to the one described in Section 2, and the same modelling assumptions were used. For the modelling of UHPFRC, the numerical model of Section 3.3 was implemented. The concrete shrinkage was simulated by a negative volumetric strain value to the UHPFRC elements [15]. Shrinkage strain value of 565 microstrains was applied to the elements of the UHPFRC layers and jackets, based on the results presented in Section 3.5 (Fig. 13b).

The interface between the Initial Beam (IB) and the UHPFRC was modeled using special two dimensional elements with a coefficient of friction equal to 1.5 and cohesion $1.9 \mathrm{MPa}$, representing a well-roughened interface [44]. The coefficient of friction used in this study (1.5) is very close to the ultimate value recommended by the Model Code 2010 [45] for very well roughened interfaces (1.4). The reliability of these numerical assumptions were examined in previous studies [46, 47]. The importance of the concrete-to-concrete shear transfer mechanisms on the overall performance of strengthened elements was also highlighted in a previous study [48]. One of the main aims of the current study is to conduct a critical comparison of the effectiveness of this novel technique with the traditional strengthening method of using additional RC layers. For this purpose, results of a previous investigation on strengthened beams with RC layers were used [7], where roughening of concrete interface was made using an air chipping hammer, and an average roughness of 2-3 $\mathrm{mm}$ was achieved. There are published recommended methods to characterise and quantify concrete surface texture [49, 50]. In this study [7], Sand Patch Test was used. Dowels were not provided, since one of the aims of this study [7] was to investigate if sufficient interface performance can be provided by interface roughening without any mechanical connectors. Also, in case of relatively 'thin' layers the use of dowels can't be easily applied since a minimum embedment length equal to six times of dowel's diameter is required [51]. Results showed that when additional RC layer is applied to the compressive side there is no need of steel connectors and, even with not so well roughened interface, the behaviour of the strengthened beam is almost monolithic [7]. In the current study, and since comparisons of the two techniques were made, exactly the same interface conditions were used for the strengthened beams with UHPFRC.

Numerical models were developed for beams strengthened with $50 \mathrm{~mm}$ layer in the tensile side (ST_UHPFR_TS) (Fig 14a), 50mm in the compressive side (ST_UHPFR_CS) (Fig 14b), and three side jacket with 50mm thickness (ST_UHPFR_3SJ) (Fig 14c).

The thickness of the additional layer/jacket was exactly the same with the thickness of the layers examined in Section 3.4. The geometry of the examined specimens is presented in Fig. 14.

In all the analyses of the strengthened with UHPFRC beams, an initial shrinkage strain value of 565 microstrains was imposed in the elements of the additional layer which is in agreement with the results presented in Fig. 13b. However, since these values are highly affected by the environmental conditions and the age of the specimens, there may be variations in the shrinkage strain values. Sensitivity analysis was conducted for the examined strengthened beams, and it was found that the response of the strengthened elements with UHPFRC was not affected considerably by variations in the shrinkage strain value of UHPFRC. Indicative results for specimens ST_UHPFR_TS without shrinkage, with 565 microstrains, and with 800 microstrains UHPFRC shrinkage strain values are presented in Fig. 15.

In the present study, shrinkage restraint was provided by the connection of the UHPFRC layer with the existing beam, and it was found that shrinkage effect was negligible. However, the effect of restrained shrinkage strain is highly affected by the degree of restraint and by the loading conditions. In previously published studies on strengthened columns with four side jackets $[15,46,52]$, the degree of restraint was much higher and the strength and stiffness of the examined columns were considerably reduced as shrinkage strain values were increased. Furthermore, in previous studies on monolithic beams [53] and columns [54], it was found that as the reinforcement amount was increased; the additional tensile stresses due to restrained shrinkage were increased, leading to reduced first cracking load values.

Numerical analyses were conducted for all the examined techniques (Fig. 14), using initial shrinkage strain value equal to 565 microstrains and four-point bending loading (Fig. 1b). The crack pattern together with the strain distribution at the ultimate strength stage for all the examined specimens is presented in Fig. 16.

The slip distribution at the interface of these specimens for $10 \mathrm{~mm}$ deflection, which is the deflection near the maximum load value for all the examined specimens, is presented in Fig. 17. From these results it can be observed that in all the examined cases the slip was maximum near the ends of the beams and 
the maximum observed slip values were; $0.93 \mathrm{~mm}$ for the specimen strengthened in the tensile side (Fig. 17a), $0.44 \mathrm{~mm}$ for the strengthened beam in the compressive side (Fig. 17b), and $0.05 \mathrm{~mm}$ for the specimen with the three side jacket (Fig. 17c). These results indicate that, in case of three side jackets, the slip was considerably reduced compared to the respective values for strengthening with a single layer in the tensile or in the compressive side.

The numerical results of the strengthened elements were compared to the respective load-deflection results of the Initial Beam $\left(\mathrm{IB}_{\text {num }}\right)$, and the results are presented in Fig. 18.

From the results of Fig. 18, the yield and the maximum load were identified and, using these values, the moment increment at yield and maximum load were calculated (Table 3 ). The plateau with the two picks of specimen ST_UHPFR_TS could be attributed to the strain hardening phase (Fig. 6) which, depending on the overall performance of the elements, can reflect to the load-deflection response.

The results indicate that the addition of UHPFRC layer in the tensile and in the compressive side had almost the same effect to the yield and ultimate moment since an increment of almost $30 \%$ was observed in both cases. The addition of a three side jacket resulted to significant increment of both yield and ultimate moments (160-180\%).

In order to investigate the effect of UHPFRC material properties on the response of the strengthened beams, a parametric study was conducted for the various strengthening techniques presented in Fig. 14. The model presented in Fig. 7 was used, with maximum tensile strength values $8 \mathrm{MPa}, 16 \mathrm{MPa}$ and the results were compared to the respective results of Fig. 18, where $12 \mathrm{MPa}$ tensile strength was assumed. Various tensile strength values were used in this parametric study in order to investigate the effect of UHPFRC with different amounts of steel fibres, since the steel fibres amount has an impact on the tensile strength.

The load deflection results of strengthened beams in the compressive side (ST_UHPFR_CS), in the tensile side (ST_UHPFR_TS), and specimens with the three side jackets (ST_UHPFR_3SJ) are presented in Fig. 19a, 19b and 19c respectively.

The results of Fig. 19 were used to calculate the ultimate moment for all the examined cases, and the distribution of the ultimate moment $\left(\mathrm{M}_{\mathrm{u}}\right)$ with the tensile strength of UHPFRC is illustrated in Fig. 20.

As it was expected, and based on the results of Fig. 20, the tensile strength of UHPFRC was not affecting the response of specimens strengthened in the compressive side (ST_UHPFR_CS) considerably, since an increment less than $4 \%$ in the ultimate moment was observed when UHPFRC tensile strength was increased from $8 \mathrm{MPa}$ to $16 \mathrm{MPa}$. In case of strengthened specimens with UHPFRC in the tensile side (ST_UHPFR_TS), the ultimate moment was increased by $31 \%$ when UHPFRC tensile strength was increased from $8 \mathrm{MPa}$ to $16 \mathrm{MPa}$. The respective increment for strengthened specimens with three side jackets (ST_UHPFRC_3SJ) was significantly higher and equal to $53 \%$.

The effect of the post-peak (softening) stress-strain behaviour of UHPFRC on the overall performance of the strengthened elements was also investigated. The softening behaviour of UHPRC is strongly dependent on the geometry of the fibres and on the fiber orientation and distribution [18]. It has been found that the post-cracking tensile strength can be increased up to $50 \%$ using appropriate fibre type and by controlling fibre distribution and orientation [18]. In the current study, two additional stress-strain models were examined using 50\% higher and 50\% lower post-peak stresses, and the results were compared to the respective of the stress-strain model which was based on the experimental results (Fig.

6). The examined models are presented in Fig. 21 and the respective load-deflection results for specimens strengthened in the tensile side (ST_UHPFR_TS), in the compressive side (ST_UHPFR_CS), and with a three side jacket (ST_UHPFR_3SJ) are illustrated in Fig. 22.

The results presented in Fig. 22 indicate that for beams strengthened in the tensile layer (ST_UHPFR_TS), when the post-peak stresses were increased by 50\%, the ultimate strength and moment were increased by $8 \%$, while when $50 \%$ lower stresses were used, the ultimate load and moment were reduced by $11 \%$. In case of beams strengthened with a three side jacket (ST_UHPFR_3SJ), the respective ultimate strength increment was $2 \%$, for $50 \%$ higher post-peak stresses, while $3 \%$ reduction was observed for $50 \%$ lower post-peak stresses. For beams strengthened in the compressive side (ST_UHPFR_CS), the effect of the post-peak behaviour was negligible, as expected, and less than $1 \%$.

\section{Strengthening with additional RC Layers. Comparisons of the two techniques}

In this section, the results of strengthened beams with UHPFRC are compared to respective experimental results of strengthened beams with traditional strengthening techniques using conventional concrete. 
The results of a previous experimental investigation [7] were used. The geometry and the material properties of the initial, prior to the strengthening beam (IB), are presented in Section 2.

Beams strengthened in the tensile side with RC layer were examined (ST_RCL_TS). In this case, strengthening was performed by adding a new concrete layer of $50 \mathrm{~mm}$ thickness in the tensile side with two bars with a diameter of $12 \mathrm{~mm}(2 \mathrm{H} 12)$ made of steel with a characteristic yielding stress value of 500 MPa were used and concrete cover of $25 \mathrm{~mm}$ (Fig. 23a). The 28 days characteristic cylinder concrete compressive strength of the layer was found equal to $39.5 \mathrm{MPa}$. The reinforcement of the layer was consisted of two bars with a diameter of $12 \mathrm{~mm}(2 \mathrm{H} 12)$ with a total amount (volume) of steel exactly the same with the total volume of steel fibres used in the layer of ST_UHPFR_TS with 3\% steel fibres and $12 \mathrm{MPa}$ average tensile strength.

Beams strengthened in the compressive zone were also examined (ST_RCL_CS) and, in this case, plain concrete layer with 28 days characteristic cylinder compressive strength of $45.4 \mathrm{MPa}$, and $50 \mathrm{~mm}$ thickness was placed on the top of the beams (Fig. 23b). In this case, a loading rate of $0.008 \mathrm{~mm} / \mathrm{s}$ was used. This loading rate is equivalent to the one used for the testing of the prisms $(0.001 \mathrm{~mm} / \mathrm{s})$ presented in section 3.4. The distance between the load and the support in the full scale elements $(750 \mathrm{~mm})$ was almost 8 times higher compared to the respective distance in the bending test of the prisms $(100 \mathrm{~mm})$ and a loading rate 8 times higher was used in order to obtain comparable results.

The beams were tested under a four-point bending as described in Section 2 and the failure pattern is illustrated in Fig. 24a and 24b for specimens ST_RCL_TS and ST_RCL_CS respectively.

The load deflection results for specimens ST_RCL_TS and ST_RCL_CS together with the experimental results of the initial beam ( $\mathrm{IB}_{\text {exp }}$ ) are presented in Fig. 25.

From the results presented in Fig. 25, the moment at yield and failure for the strengthened specimens were calculated together with the respective increment, in comparison with the Initial Beam's (IB) results of Table 3 (Table 4). In case of ST_RCL_TS, the yielding moment was defined by the yielding of the reinforcement of the additional layer, which occurs before the yielding of the reinforcement of the initial beam.

These results were compared to the respective values calculated for the beams strengthened with UHPFRC with $12 \mathrm{MPa}$ ultimate tensile strength, and the comparisons of $\mathrm{M}_{\mathrm{y}}$ and $\mathrm{M}_{\mathrm{u}}$ for the various techniques are presented in Fig. 26a and Fig. 26b.

The results of Fig. 26 indicate that very high moment increments were observed for beams strengthened with an additional RC layer in the tensile side (ST_RCL_TS), since increments of $150 \%$ and 97\% were observed for $\mathrm{M}_{\mathrm{y}}$ and $\mathrm{M}_{\mathrm{u}}$. The respective increments for specimens strengthened with UHPFRC in the tensile side (ST_UHPFRC_TS) were found to be lower and equal to $29 \%$ and $31 \%$. The results of Fig. 26 indicate that the highest moment increment was observed for a three side UHPFRC jacket and this was found equal to $167 \%$ and $178 \%$ for $\mathrm{M}_{\mathrm{y}}$ and $\mathrm{M}_{\mathrm{u}}$ respectively.

In case of beams strengthened in the compressive zone, application of UHPFRC (ST_UHPFRC_CS) resulted to an increment of $19 \%$ and $28 \%$ for $\mathrm{My}$ and $\mathrm{Mu}$, while the respective increment was slightly lower $\left(25 \%\right.$ for $\mathrm{M}_{\mathrm{y}}$ and $22 \%$ for $\mathrm{M}_{\mathrm{u}}$ ) when normal concrete was used (ST_RCL_CS).

The technique of strengthening in the tensile side with combination of UHPFRC layer and two steel bars was also examined. The same geometry and reinforcement with the one presented in Fig. 23a was used with the only difference that instead of normal concrete, UHPFRC with $12 \mathrm{MPa}$ ultimate tensile stress was used (ST_UHPFRC_TS_12 MPa \& steel bars). The load deflection results were compared to the respective results of ST_RCL_TS and with the initial, prior to strengthening, beam (IB) (Fig. 27).

The results presented in Fig. 27 indicate that the initial stiffness and the ultimate load capacity were increased when conventional concrete was replaced by UHPFRC in reinforced concrete layers applied to the tensile side. The increment of the yield and ultimate bending moment values are presented in Table 5.

The results of Table 5 indicate that there is an increment of $7 \%$ in the yield bending moment and $9 \%$ in the ultimate bending moment when the normal concrete of the layer is replaced by UHPFRC. The results indicate that even if the performance is overall enhanced, the contribution of the UHPFRC in this case was not fundamental.

\section{Conclusions}

In this study, extensive experimental and numerical investigation was conducted to investigate the efficiency of UHPFRC for the strengthening of existing beams. Mechanical testing and shrinkage strain measurements were conducted in order to determine UHPFRC material properties, and these results were used for the numerical modelling. The following two conclusions were drawn regarding the behavior of UHPFRC in tension and regarding the shrinkage strain. 
- The proposed stress-strain model in tension, which was consisted of an initial linear elastic part and a tri-linear post elastic behaviour can accurately predict the response of UHPFRC.

- Shrinkage strain measurements were also presented for UHPFRC with 3\% steel fibres and without steel fibres. The shrinkage strain was 30\% reduced in case of UHPFRC with $3 \%$ steel fibres, compared to the respective measurements of plain UHPC.

Extensive numerical modelling was conducted on beams strengthened with UHPFRC. Strengthened beams with additional layer in the compressive, in the tensile side, and with a three side jacket were examined. A parametric study with different values of UHPFRC tensile strength was also conducted and the following observations were made.

- As expected, in case of specimens strengthened with UHPFRC in the compressive side, increment of the tensile strength of UHPFRC was not considerably affecting the response of the strengthened specimens. Ultimate moment increment less than $4 \%$ was observed when UHPFRC tensile strength was increased from $8 \mathrm{MPa}$ to $16 \mathrm{MPa}$.

- In case of strengthened specimens with UHPFRC in the tensile side, the ultimate moment was increased by $31 \%$ when UHPFRC tensile strength was increased from $8 \mathrm{MPa}$ to $16 \mathrm{MPa}$.

- The respective increment for strengthened specimens with three side jackets (ST_UHPFRC_3SJ) was significantly higher and equal to $53 \%$.

The effect of the post-peak (softening) stress-strain behaviour of UHPFRC on the overall performance of the strengthened beams was also investigated.

- As expected, for beams strengthened in the compressive side, the effect of the post-peak behaviour of the tensile stress-strain model was negligible.

- In case of beams strengthened in the tensile layer with UHPFRC layer, when the stresses in the post-peak branch were increased by $50 \%$, the ultimate strength and moment were increased by $8 \%$, while, when $50 \%$ lower stresses were used, the ultimate load and moment were reduced by $11 \%$.

- In case of beams strengthened with a three side jacket the respective ultimate strength increment was $2 \%$, for $50 \%$ higher post-peak stresses, while reduction equal to $3 \%$ was observed for stressstrain model with $50 \%$ lower post-peak stresses.

Sensitivity analysis was also conducted for the examined strengthened with UHPFRC beams, using different shrinkage strain values for UHPFRC. The main conclusion of this study was that in this case the response of the strengthened elements was not affected considerably by variations in the shrinkage strain value of UHPFRC.

Critical comparisons of this novel technique with the traditional method of strengthening with RC layers were also conducted and the following conclusions regarding the efficiency of the two techniques were drawn.

- The highest moment increment was observed for a three side UHPFRC jacket and this was found to be equal to $167 \%$ and $178 \%$, for $\mathrm{M}_{\mathrm{y}}$ and $\mathrm{M}_{\mathrm{u}}$ respectively. When three side jacket was used, the slip at the interface was considerably reduced, compared to the respective values of beams strengthened in the compressive or tensile side.

- The increment in case of specimens strengthened with UHPFRC in the tensile side was found equal to $29 \%$ and $31 \%$ for $\mathrm{M}_{\mathrm{y}}$ and $\mathrm{M}_{\mathrm{u}}$. Considerably higher increment was observed in case of beams strengthened with an additional RC layer in the tensile side (150\% increment of $\mathrm{M}_{\mathrm{y}}$ and $97 \%$ increment of $\mathrm{M}_{\mathrm{u}}$ ).

- In case of beams strengthened in the compressive zone, the addition of UHPFRC resulted to an increment of My and $\mathrm{Mu} 29 \%$ and 28\% respectively, while the increment was slightly lower ( $25 \%$ for $\mathrm{M}_{\mathrm{y}}$ and $22 \%$ for $\mathrm{M}_{\mathrm{u}}$ ) when normal concrete was used, which indicates that there is no need for high strength concretes when strengthening in the compressive zone.

For beams strengthened in the tensile side, combination of steel bars and UHPFRC was also investigated and an increment of $7 \%$ in the yield bending moment and $9 \%$ in the ultimate bending moment was observed, compared to the respective values of beam strengthened with RC layers. The results indicate that even if the performance is overall enhanced, the contribution of the UHPFRC in this case was not fundamental.

The main conclusion of this study is that superior performance can be achieved by the use of three sides UHPFRC jackets. In practise, UHPFRC could be used following the same procedure with the one used for RC jackets. The application of UHPFRC could be done using formworks by adapting the rheological properties of UHPFRC [26]. This novel technique has a great potential for the structural upgrade of the existing structures. 


\section{Acknowledgments}

The authors would like to express their gratitude to Dr David Pope for his assistance during the testing, and they would also like to acknowledge Hanson Heidelberg Cement Group and Sika Limited for providing raw materials. The authors would also like to thank the anonymous reviewers for their valuable comments and suggestions which have considerably improved the manuscript.

\section{References}

[1] Julio ES, Branco F, Silva VD. Structural rehabilitation of columns with reinforced concrete jacketing. J Prog Struct Eng Mat 2003;5:29-37.

[2] Julio ES, Branco F, Silva VD. Reinforced concrete jacketing -interface influence on monotonic loading response. ACI Structural Journal 2005; 102(2):252-257.

[3] Trikha D, Jain S, Hali S. Repair and strengthening of damaged concrete beams. Concrete International Design and Construction 2011;13(6):53-59.

[4] Cheon HK, MacAlevey N. Experimental behaviour of jacketed reinforced concrete beams. ASCE Journal of Structural Engineering 2000;126:692-699.

[5] Altun F. An experimental study of jacketed reinforced concrete beams under bending. Construction and Building Materials 2004;18:611-618.

[6] Tsioulou O, Dritsos S. A Theoretical Model to Predict Interface Slip due to Bending. RILEM Materials and Structures 2011;44(4): 825-843.

[7] Tsioulou O, Lampropoulos A, Dritsos S. Experimental investigation of interface behaviour of RC beams strengthened with concrete layers. Construction and Building Materials 2013;40:50-59.

[8] Yuan Y, Marosszeky M. Restrained Shrinkage in Repaired Reinforced Concrete Elements. Materials and Structures 1994;27(7):375-382.

[9] Silfwerbrand J. Stresses and Strains in Composite Concrete Beams Subjected to Differential Shrinkage. ACI Structural Journal 1997; 94(4):347-353.

[10] Denarie E, Silfwerbrand J. Structural Behaviour of Bonded Concrete Overlays. Proceedings of the International RILEM Workshop on Bonded Concrete Overlays, Stockholm, 7-8 June 2004. Sweden.

[11] Abbasnia R, Godossi P, Ahmadi J. Prediction of Restrained Shrinkage Based on Restraint Factors in Patching Repair Mortar. Cement and Concrete Research 2005;35 (2005):1909-1913.

[12] Beushausen H, Alexander MG. Failure Mechanisms and Tensile Relaxation of Bonded Concrete Overlays Subjected to Differential Shrinkage. Cement and Concrete Research 2006;36:1908-1914.

[13] Beushausen H, Alexander MG. Localised Strain and Stress in Bonded Concrete Overlays Subject to Differential Shrinkage. Materials and Structures 2007;40:189-199.

[14] Zhou J, Ye G, Schlangen E, Breugel K. Modelling of Stresses and Strains in Bonded Concrete Overlays Subjected to Differential Volume Changes. Theoretical and Applied Fracture Mechanics 2008;49:199-205.

[15] Lampropoulos A, Tsioulou O, Dritsos S. Biaxial Stress due to Shrinkage in Concrete Jackets of Strengthened Columns. ACI Materials Journal 2012;109(3):331-340.

[16] Kang ST, Lee Y, Park YD, Kim JK. Tensile fracture properties of an Ultra High Performance Fiber Reinforced Concrete (UHPFRC) with steel fiber. Composite Structures 2010;92(1):61-71.

[17] Yoo Y, Shin HO, Yang JM, Yoon YS. Material and bond properties of Ultra High Performance Fiber Reinforced Concrete with micro steel fibers. Composites Part B: Engineering 2013;58:22-133.

[18] Kang ST, Kim JK. The relation between fiber orientation and tensile behavior in an Ultra High Performance Fiber Reinforced Cementitious Composites (UHPFRCC). Cement and Concrete Research 2011; 41(10):1001-1014.

[19] Hassan A, Jones S, Mahmud G. Experimental test methods to determine the uniaxial tensile and compressive behaviour of ultra high performance fibre reinforced concrete (UHPFRC). Construction and Building Materials 2012;37:874-882.

[20] Toledo Filho R, Koenders E, Formagini S, Fairbairn E. Performance assessment of Ultra-High Performance Fibre Reinforced Cementitious Composites in view of sustainability. Materials and Design 2012;36:880-888.

[21] Habel K, Viviani M, Denarié E, Brühwiler E. Development of the mechanical properties of an UltraHigh Performance Fiber Reinforced Concrete (UHPFRC). Cement and Concrete Research 2006;36:1362-1370. 
[22] Neocleous K., Tlemat H., Pilakoutas K. Design issues for concrete reinforced with steel fibres including fibres recovered from used Tires. Journal of Materials in Civil Engineering ASCE 2006;18(5):677-685.

[23] Ferrara L, Ozyurt N, di Prisco M. High mechanical performance of fibre reinforced cementitious composites: the role of "casting-flow induced" fibre orientation. Material and Structures 2011;44(1):109-128.

[24] Farhat FA, Nicolaides D, Kanelopoulos A, Karihaloo BL. High performance fibre-reinforced cementitious composite (CARDIFRC) - Performance and application to retrofitting. Engineering Fracture Mechanics 2007; 74(1-2):151-167.

[25] Bruhwiller E, Denarie E. Rehabilitation of concrete structures using Ultra-High Performance Fibre Reinforced Concrete. The Second International Symposium on Ultra High Performance Concrete, Kassel, 5-7 March 2008. Germany.

[26] Brühwiler E. Rehabilitation and strengthening of concrete structures using Ultra-High Performance Fibre Reinforced Concrete' Concrete Repair, Rehabilitation and Retrofi tting III, Cape town, 3-5 September 2012, South Africa.

[27] Habel K, Denarié E, and Brühwiler E. Structural response of elements combining ultrahighperformance fiber-reinforced concretes and reinforced concrete.' ASCE Structural journal 2006: 1793-1800.

[28] Noshiravani T, and Brühwiler E. Analytical Model for Predicting Response and Flexure-Shear Resistance of Composite Beams Combining Reinforced Ultrahigh Performance Fiber-Reinforced Concrete and Reinforced Concrete. ASCE Structural journal 2014, 140(6), 04014012.

[29] Beschi C., Meda A., Riva P. Beam-Column Joint Retrofitting with High Performance Fiber Reinforced Concrete Jacketing, Applied Mechanics and Materials 2011;82:577-582.

[30] Magri A., Colombo M., and di Prisco M. TRM and UHPFRC: Retrofitting solutions for structural elements. Concrete Repair, Rehabilitation and Retrofi tting III, Cape town, 3-5 September 2012, South Africa.

[31] Lampropoulos A, Paschalis S, Tsioulou O, Dritsos S. Strengthening of existing reinforced concrete beams using ultra high performance fibre reinforced concrete. International Conference on Concrete Repair, Rehabilitation and Retrofitting (ICCRRR), Leipzig, 5-7 October 2015, Germany.

[32] Cervenka V, Jendele L, Cervenka J. ATENA Program Documentation: Part 1 Theory. Czech Republic, Prague; 2013.

[33] Model Code 1990. CEB-FIP; 1993 Thomas Telford, London. UK.

[34] Paschalis S, Lampropoulos A. Size effect on the flexural performance of Ultra High Performance Fiber Reinforced Concrete (UHPFRC). HPFRCC-7 7th RILEM Conference on High Performance Fiber Reinforced Cement Composites, Stuttgart, 1-3 June 2015, Germany.

[35] Graybeal B. Compressive Behavior of Ultra-High-Performance Fiber-Reinforced Concrete. ACI Materials Journal 2007;104(2):146-152.

[36] AFGC-SETRA. Ultra high performance fibre-reinforced concretes. Interim Recommendations, SETRA, Bagneux, 2002, France.

[37] JSCE. Recommendations for design and construction of ultra-high strength fiber reinforced concrete structures (Draft). Japan Society of Civil Engineers, Tokyo, 2004, Japan.

[38] EN 14651:2005 2005. Test method for metallic fibered concrete - Measuring the flexural tensile strength (limit of proportionality (LOP), residual).

[39] ASTM C1609 / C1609M-05, Standard Test Method for Flexural Performance of Fiber-Reinforced Concrete (Using Beam With Third-Point Loading), ASTM International, West Conshohocken, PA, 2005.

[40] DIN 50014-Climates and Their Technical Application, Standard Climates. (in German)

[41] Yoo DY, Min KH, Lee JH, Yoon YS. Shrinkage and cracking of restrained ultra-high-performance fiber-reinforced concrete slabs at early age. Construction and Building Materials 2014;73:357-365.

[42] Kamen A. Time dependent behaviour of Ultra High Performance Fibre Reinforced Concrete (UHPFRC). 6th International PhD Symposium in Civil Engineering, Zurich, 23-26 August 2006, Switzerland.

[43] Kamen A, Denarié E, Sadouki H, Brühwiler E. Thermo-mechanical response of UHPFRC at early age-Experimental study and numerical simulation. Cement and Concrete Research 2008;38:822831.

[44] CEB, CEB Bulletin no. 162: assessment of concrete structures and design procedures for upgrading (redesign), Paris, 1983. 
[45] CEB-FIP (Comité Euro International du Béton; Fédération International de la Précontraint). 2010. fib Bulletin 55: Model Code 2010, Volume 1. Lausanne: International Federation for Structural Concrete (fib).

[46] Lampropoulos AP, Dritsos SE. Concrete Shrinkage Effect on Columns Strengthened with Concrete Jackets. Structural Engineering International 2010;20 (3):234-239.

[47] Lampropoulos AP, Dritsos SE. Modelling of RC Columns Strengthened with RC Jackets. Journal of Earthquake Engineering and Structural Dynamics 2011; 40 (15):1689-1705.

[48] Vandoros KG, Dritsos SE. Concrete jacket construction detail effectiveness when strengthening RC columns. Construction and Building Materials 2008;22(3):264-276.

[49] Santos P, Júlio ES. Comparison of methods for texture assessment of concrete surfaces. ACI Materials Journal 2010;107(5):433-40.

[50] Santos P, Julio ES. A state-of-the-art review on roughness quantification methods for concrete surfaces. Construction and Building Materials 2013;38:912-923.

[51] Greek Code of Interventions. Greek Organization for Seismic Planning and Protection. Athens: Greek Ministry for Environmental Planning and Public Works; 2012.

[52] Lampropoulos AP, Paschalis S, Dritsos SE. UHPFRC versus RC jackets for the seismic upgrade of columns. IABSE Conference 'Structural Engineering: Providing Solutions to Global Challenges', Geneva, 23-25 September 2015, Switzerland.

[53] Yoo DY, Yoon YS. Structural performance of ultra-high-performance concrete beams with different steel fibers. Engineering Structures 2015;102:409-423.

[54] Lampropoulos AP, Dritsos SE. Concrete shrinkage effect on the behavior of RC columns under monotonic and cyclic loading. Construction and Building Materials 2011;25 (4):1596-1602. 


\section{List of tables}

Table 1

UHPFRC Mix design

\begin{tabular}{cc}
\hline Material & Mix proportions $(\mathrm{Kg} / \mathrm{m} 3)$ \\
\hline Cement (52.5 N) & 657 \\
GGBS & 418 \\
Silica fume & 119 \\
Silica Sand & 1051 \\
Superplasticizers & 59 \\
Water & 185 \\
$3 \%$ Steel Fibres (13 mm length and 0.16 & 236 \\
mm diameter) & \\
\hline
\end{tabular}

Table 2

Comparisons of the mechanical performance with other studies from the literature

\begin{tabular}{|c|c|c|c|c|c|c|c|c|}
\hline \multirow{2}{*}{$\begin{array}{c}\text { Research } \\
\text { study }\end{array}$} & \multirow[b]{2}{*}{ Cement } & \multicolumn{2}{|c|}{ inder $\left(\mathrm{Kg} / \mathrm{m}^{3}\right)$} & \multirow{2}{*}{$\begin{array}{l}\text { Water/ } \\
\text { Binder }\end{array}$} & \multirow{2}{*}{$\begin{array}{c}\begin{array}{c}\text { Steel } \\
\text { fibres }\end{array} \\
\text { (Vol.\%) }\end{array}$} & \multirow{2}{*}{$\begin{array}{c}\text { Compressive } \\
\text { strength } 28 \mathrm{~d}\end{array}$} & \multirow{2}{*}{$\begin{array}{c}\begin{array}{c}\text { Tensile } \\
\text { strength }\end{array} \\
(\mathrm{MPa})\end{array}$} & \multirow{2}{*}{$\begin{array}{c}\begin{array}{c}\text { Young's } \\
\text { Modulus }\end{array} \\
(\mathrm{GPa})\end{array}$} \\
\hline & & GGBS & $\begin{array}{l}\text { Sillica } \\
\text { fume }\end{array}$ & & & & & \\
\hline $\begin{array}{c}\text { Hassan } \\
\text { et.al. [19] }\end{array}$ & 657 & 418 & 119 & 0.15 & 2 & 151 & 7 & 46 \\
\hline $\begin{array}{c}\text { Toledo } \\
\text { et.al. [20] }\end{array}$ & 1011 & 0 & 58 & 0.19 & 2 & 156 & 10 & 47.7 \\
\hline $\begin{array}{c}\text { Habel et.al. } \\
\text { [21] }\end{array}$ & 1050 & 0 & 275 & 0.14 & 6 & 168 & 11 & 48 \\
\hline $\begin{array}{c}\text { Current } \\
\text { study }\end{array}$ & 657 & 418 & 119 & 0.15 & 3 & 164 & 12 & 57.5 \\
\hline
\end{tabular}

Table 3

Yield and ultimate bending moment values and the respective increment for all the examined specimens

\begin{tabular}{lllll}
\hline Specimen & $\mathrm{M}_{\mathrm{y}}\left(10^{3} \mathrm{Nm}\right)$ & $\Delta \mathrm{M}_{\mathrm{y}} / \mathrm{M}_{\mathrm{y}, \mathrm{IB}}(\%)$ & $\mathrm{M}_{\mathrm{u}}\left(10^{3} \mathrm{Nm}\right)$ & $\Delta \mathrm{M}_{\mathrm{u}} / \mathrm{M}_{\mathrm{u}, \mathrm{IB}}(\%)$ \\
\hline $\mathrm{IB}_{\text {num }}$ & 24 & - & 32 & - \\
ST_UHPFR_CS & 31 & 29 & 41 & 28 \\
ST_UHPFR_TS & 31 & 29 & 42 & 31 \\
ST_UHPFR_3SJ & 64 & 167 & 89 & 178
\end{tabular}

Table 4

Yield and ultimate bending moment values and the respective increment for ST_RCL_CS and ST_RCL_TS

\begin{tabular}{lllll}
\hline Specimen & $\mathrm{M}_{\mathrm{y}}\left(10^{3} \mathrm{Nm}\right)$ & $\Delta \mathrm{M}_{\mathrm{y}} / \mathrm{M}_{\mathrm{y}, \mathrm{IB}}(\%)$ & $\mathrm{M}_{\mathrm{u}}\left(10^{3} \mathrm{Nm}\right)$ & $\Delta \mathrm{M}_{\mathrm{u}} / \mathrm{M}_{\mathrm{u}, \mathrm{IB}}(\%)$ \\
\hline ST_RCL_CS & 30 & 25 & 39 & 22 \\
ST_RCL_TS & 60 & 150 & 63 & 97
\end{tabular}


Table 5

Yield and ultimate bending moment values and the respective increment for ST_RCL_TS and ST_UHPFRC_TS_12 MPa \& steel bars

\begin{tabular}{lllll}
\hline Specimen & $\mathrm{M}_{\mathrm{y}}$ & $\begin{array}{l}\Delta \mathrm{M}_{\mathrm{y}} / \mathrm{M}_{\mathrm{y}, \mathrm{IB}} \\
(\%)\end{array}$ & $\begin{array}{l}\mathrm{M}_{\mathrm{u}} \\
\left(10^{3} \mathrm{Nm}\right)\end{array}$ & $\begin{array}{l}\Delta \mathrm{M}_{\mathrm{u}} / \mathrm{M}_{\mathrm{u}, \mathrm{IB}} \\
(\%)\end{array}$ \\
\hline ST_UHPFRC_TS_12 MPa \& steel bars & 64 & 160 & 68 & 106 \\
ST_RCL_TS & 60 & 150 & 63 & 97 \\
\hline
\end{tabular}




\section{List of figure captions}

Fig. 1. (a) Geometry and (b) testing setup of IB [7]

Fig. 2. Compression SBETA constitutive model adopted in ATENA software [32]

Fig. 3. Numerical versus experimental results for IB

Fig. 4. Direct tensile tests (a) geometry and (b) experimental setup

Fig. 5. Stress-strain results for the direct tensile tests

Fig. 6. Direct tensile tests monitoring using Digital Image Correlation System

Fig. 7. Tensile stress strain behaviour adopted in the numerical model for the simulation of UHPFRC

Fig. 8. Finite element model and strain/crack distribution in the direct tensile test specimens

Fig. 9. Numerical versus experimental results for dog-bone direct tensile tests

Fig. 10. (a) Setup of the flexural testing of UHPFRC and (b) typical crack pattern after the end of the test

Fig. 11. (a) Numerical model and (b) strain and crack distribution

Fig. 12. Numerical versus experimental load-deflection results of UHPFRC layers under flexural testing

Fig. 13. (a) Shrinkage strain measurements setup and (b) shrinkage strain versus age

Fig. 14. Geometry of strengthened beams with UHPFRC in (a) the tensile side, (b) the compressive side, and (c) three side jacket

Fig. 15. Numerical results for ST_UHPFR_TS using different shrinkage strain values

Fig. 16. Crack pattern and strain distribution for (a) ST_UHPFR_TS, (b) ST_UHPFR_CS, and (c) ST_UHPFR_3SJ

Fig. 17. Interface distribution slip (m) in strengthened beams with UHPFRC in (a) the tensile side, (b) the compressive side, and (c) three side jacket

Fig. 18. Numerical results for strengthened beams and for the Initial Beam (IB)

Fig. 19. Numerical results for (a) ST_UHPFR_CS, (b) ST_UHPFR_TS, and (c) ST_UHPFR_3SJ with various UHPFRC tensile strength values

Fig. 20. Ultimate moment $\left(\mathrm{M}_{\mathrm{u}}\right)$ for the strengthened elements with various UHPFRC tensile strength values

Fig. 21. Examined tensile stress strain models with various post-peak characteristics for UHPFRC

Fig. 22. Numerical results for (a) ST_UHPFR_CS, (b) ST_UHPFR_TS, and (c) ST_UHPFR_3SJ with various UHPFRC post-peak characteristics

Fig. 23. Geometry of strengthened elements (a) ST_RCL_TS and (b) ST_RCL_CS

Fig. 24. Failure crack patter for (a) ST_RCL_TS and (b)ST_RCL_CS

Fig. 25. Load-deflection results for IB, ST_RCL_TS and ST_RCL_CS

Fig. 26. Increment of the moment (a) at yield and (b) at failure (\%) for the various examined techniques

Fig. 27. Load-deflection results for ST_RCL_TS and ST_UHPFRC_TS_12 MPa \& steel bars 


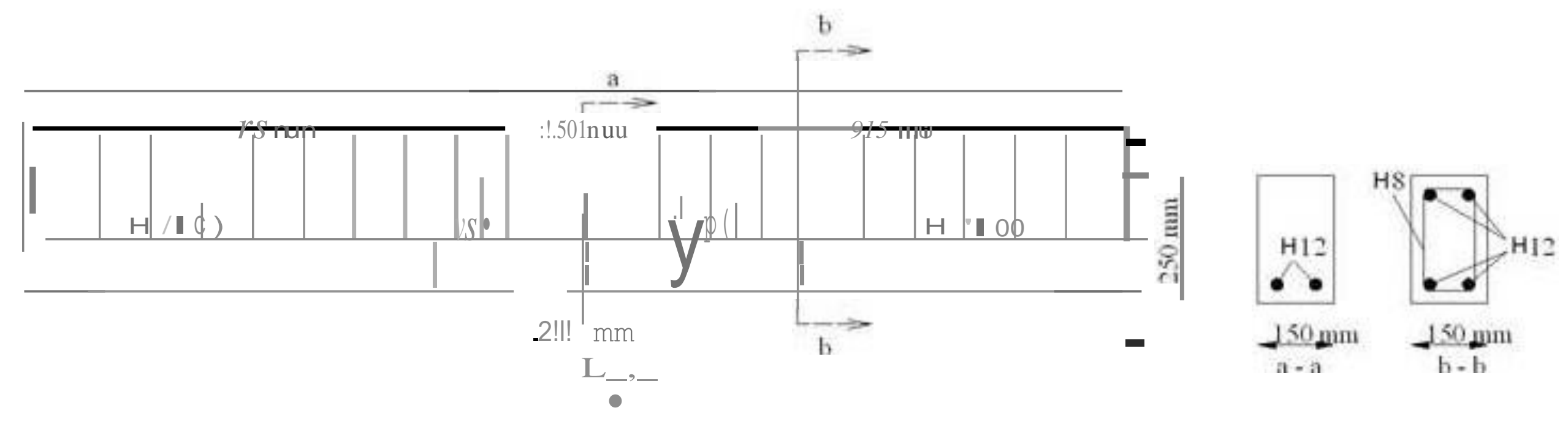




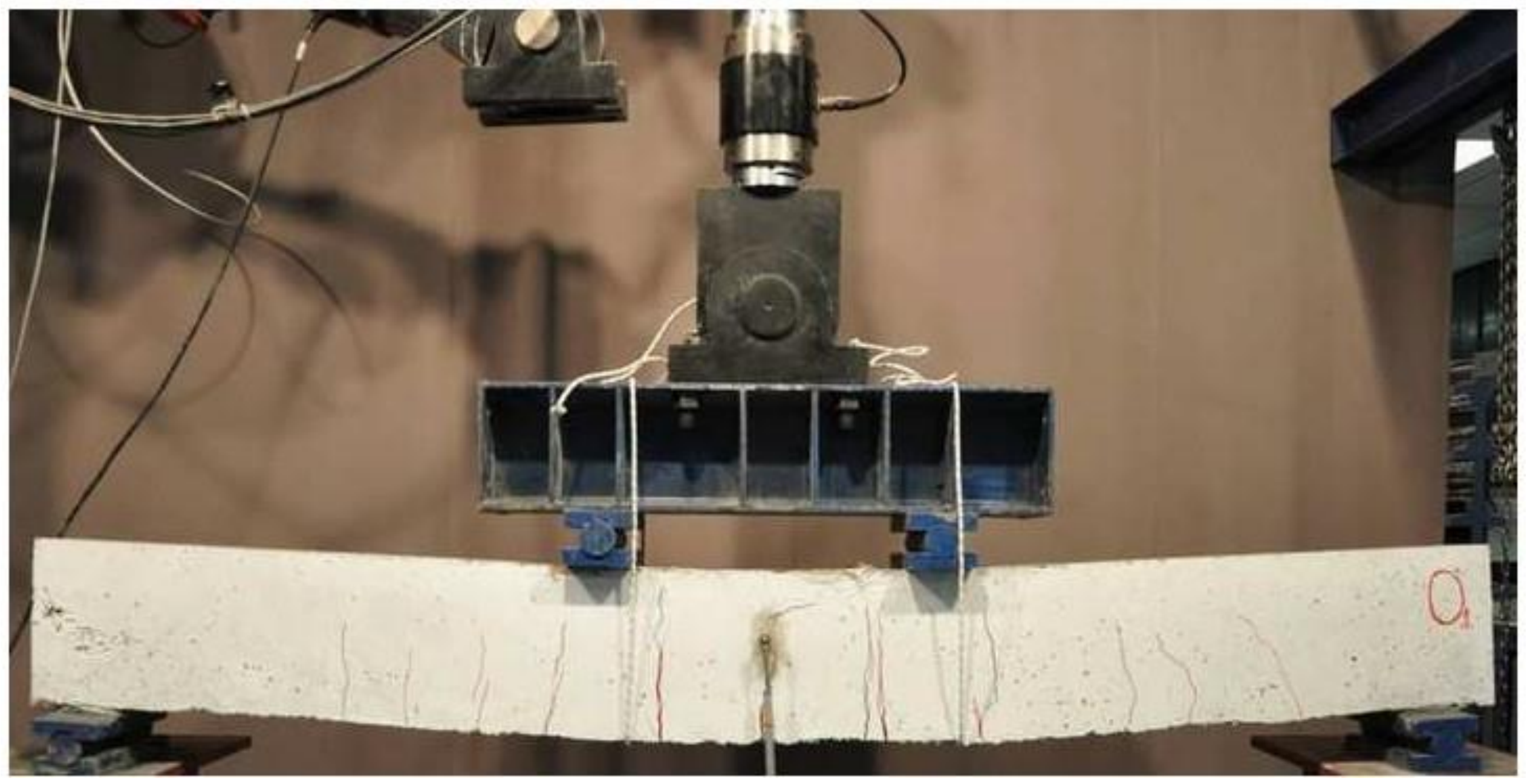


Compressive strain

Linearly descending using SBETA fictitious compression plane model

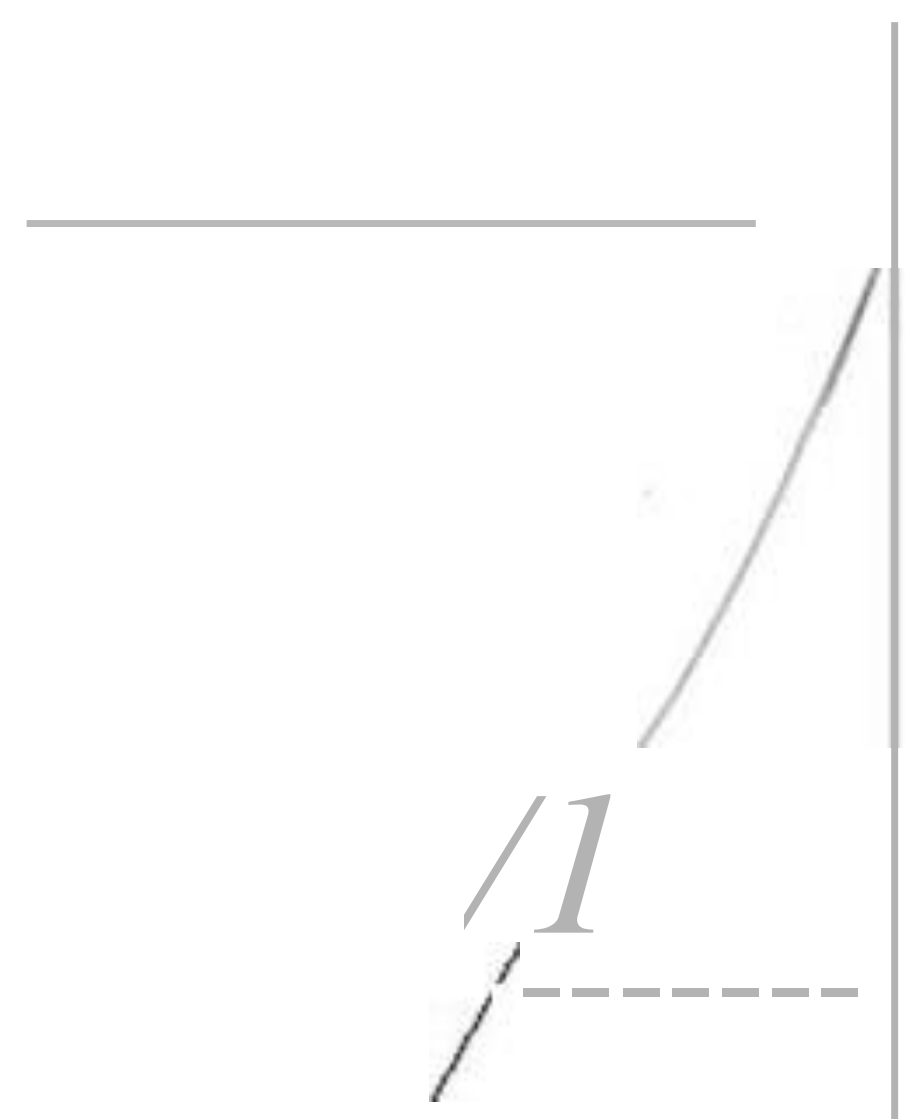

CEB-FIP Model Code 90
Compressive stress 


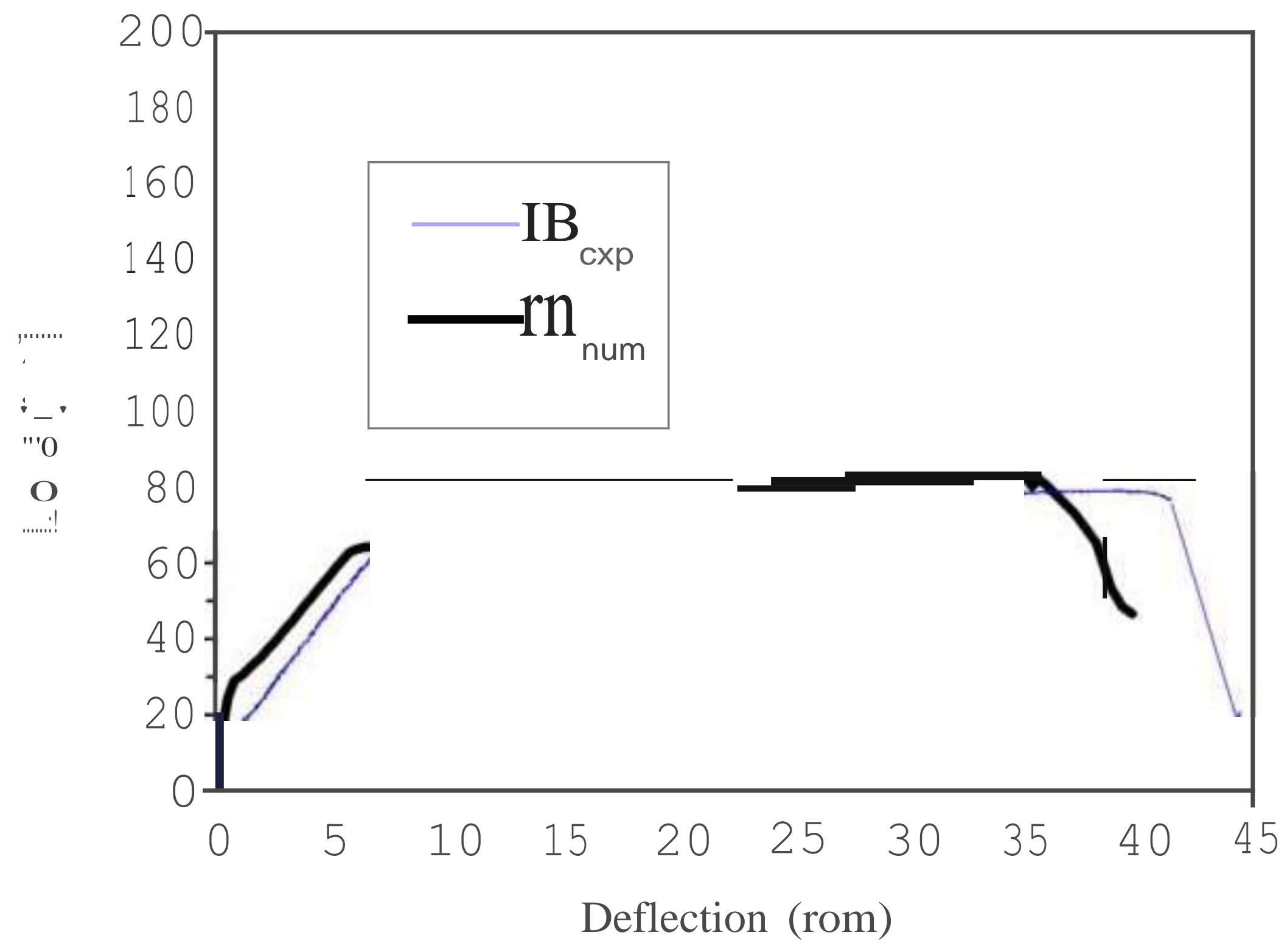


$.40 \mathrm{~mm}$.

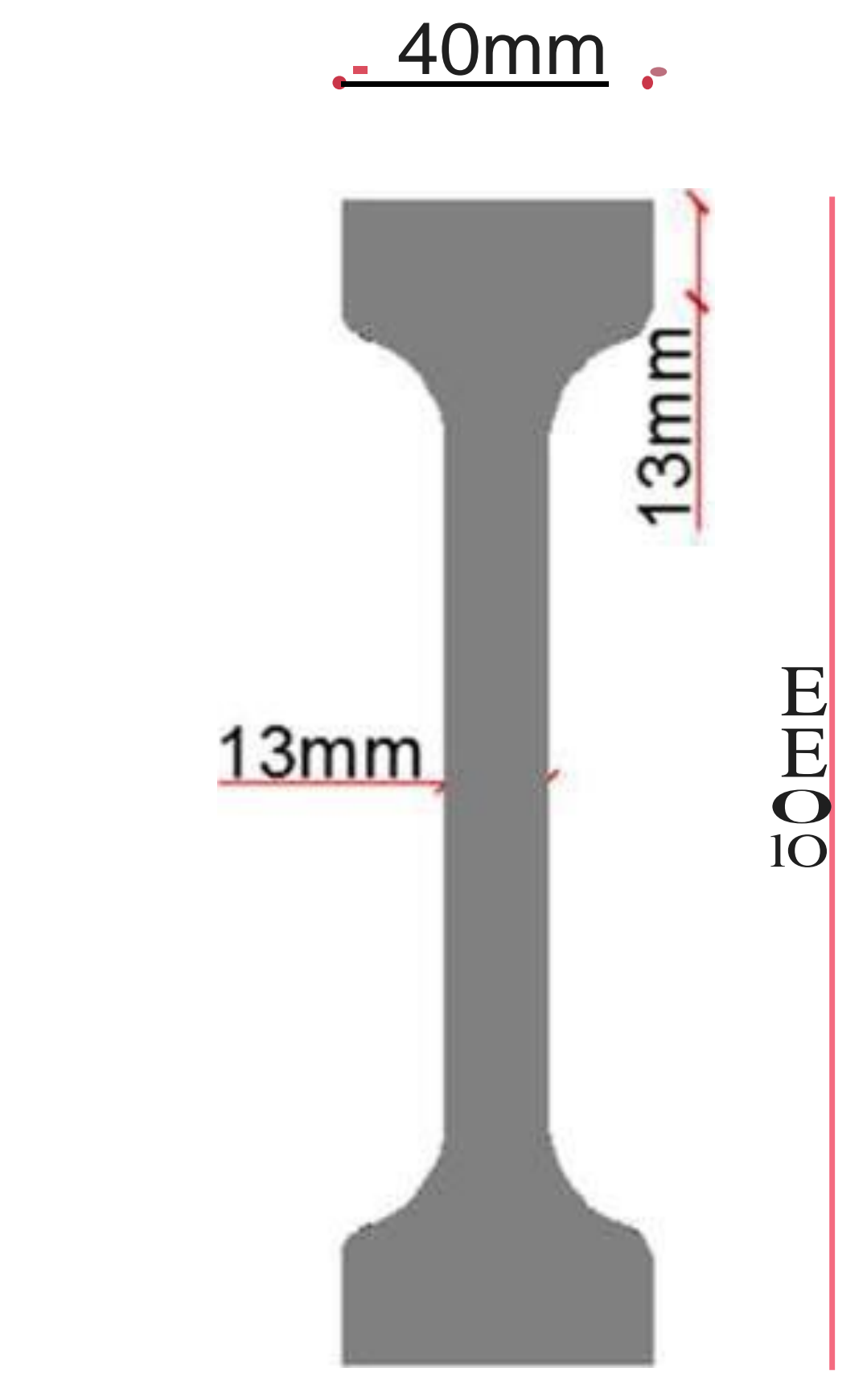

$50 \mathrm{~mm}$
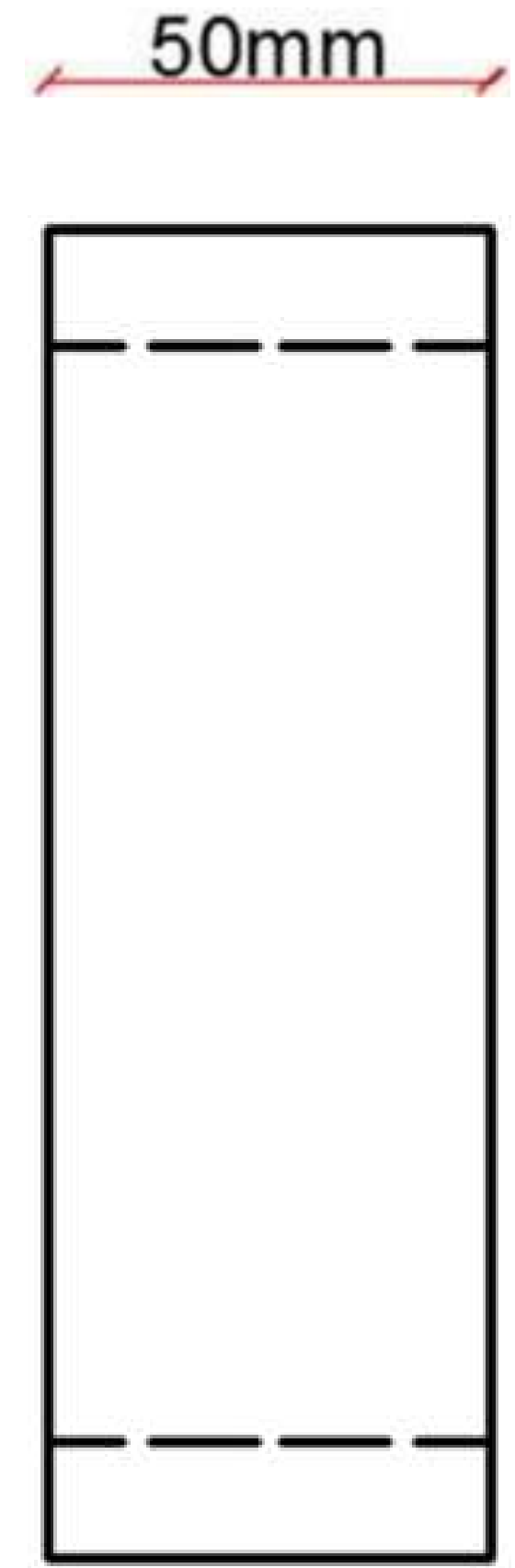

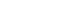


Fig.4b

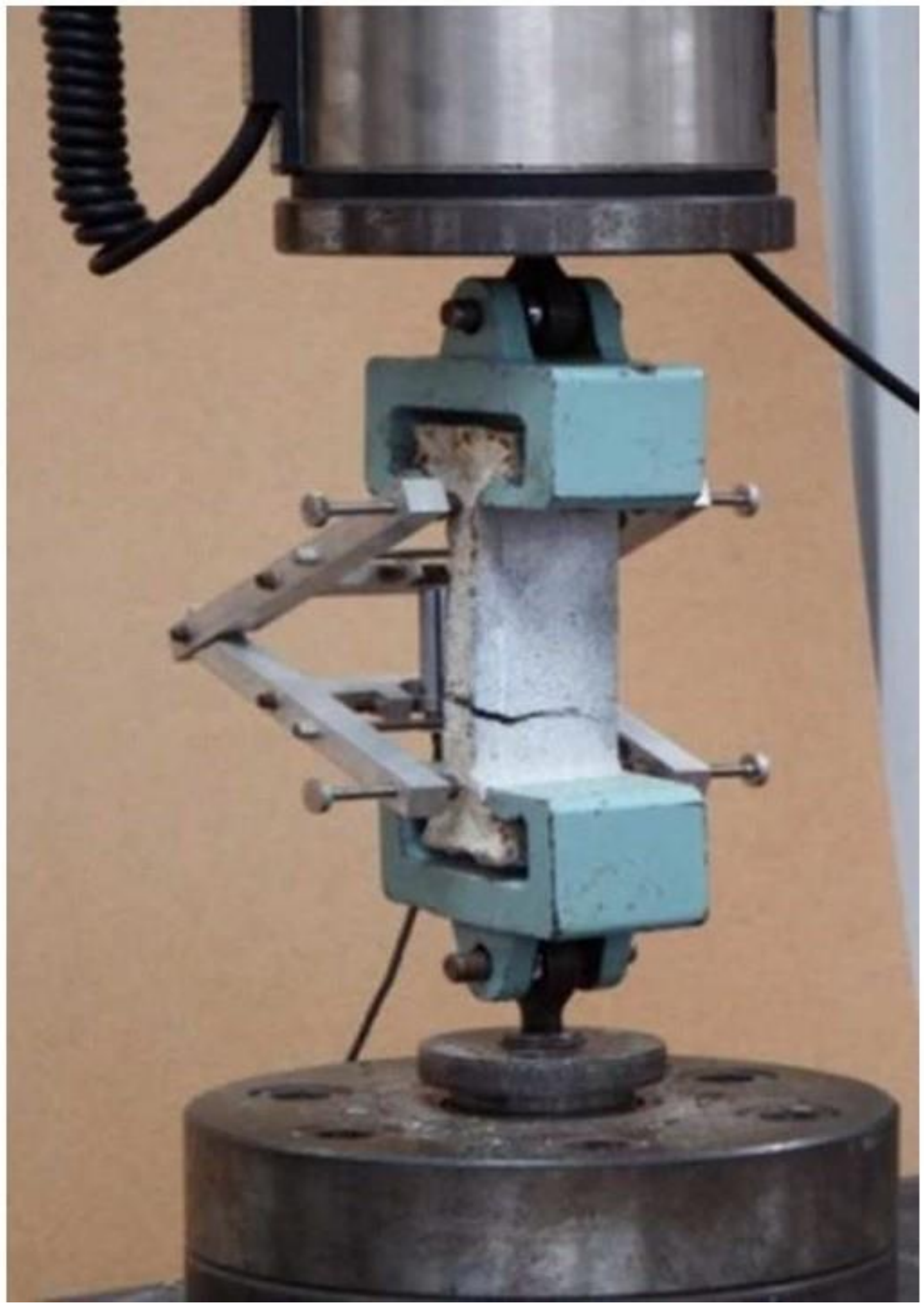




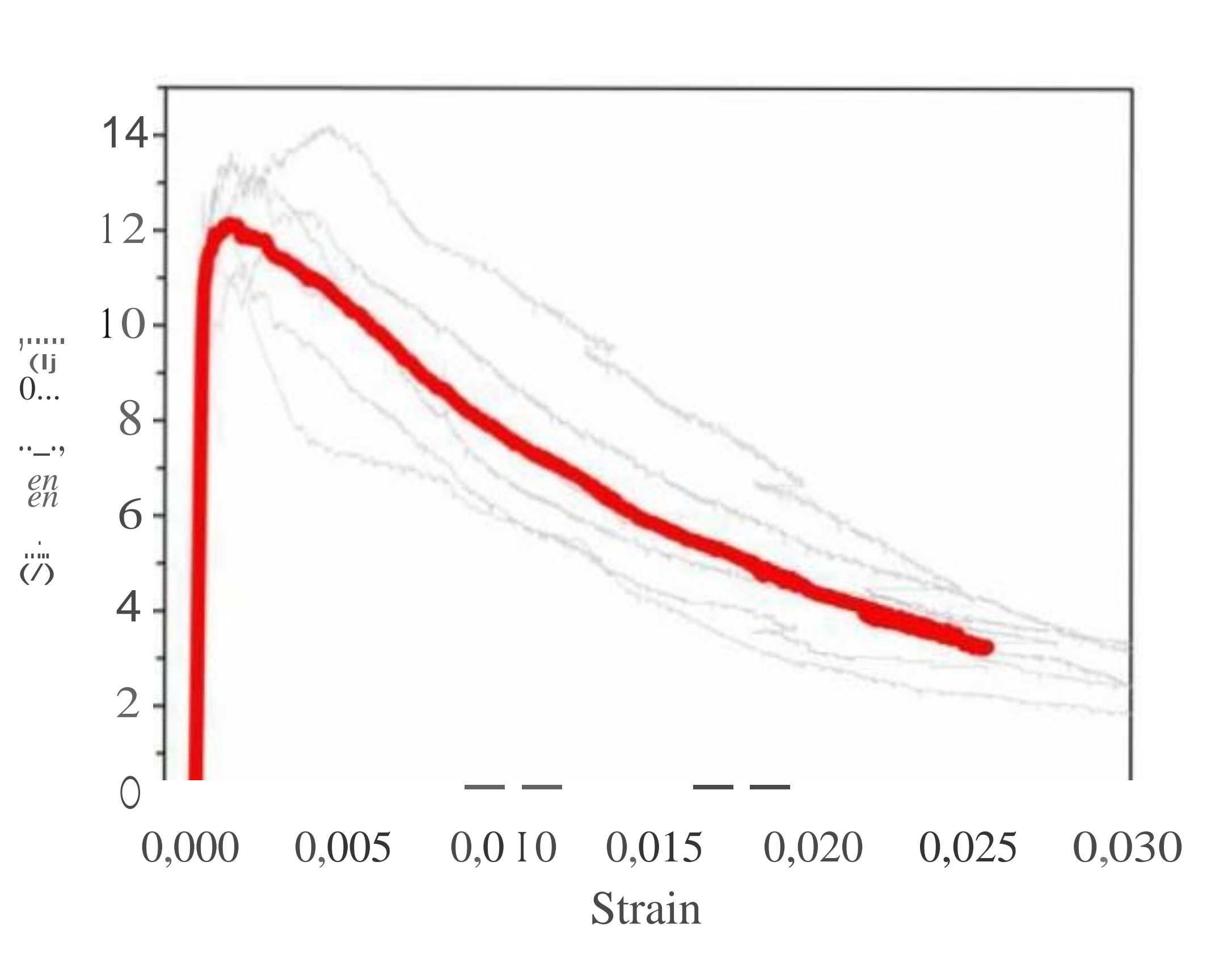

.
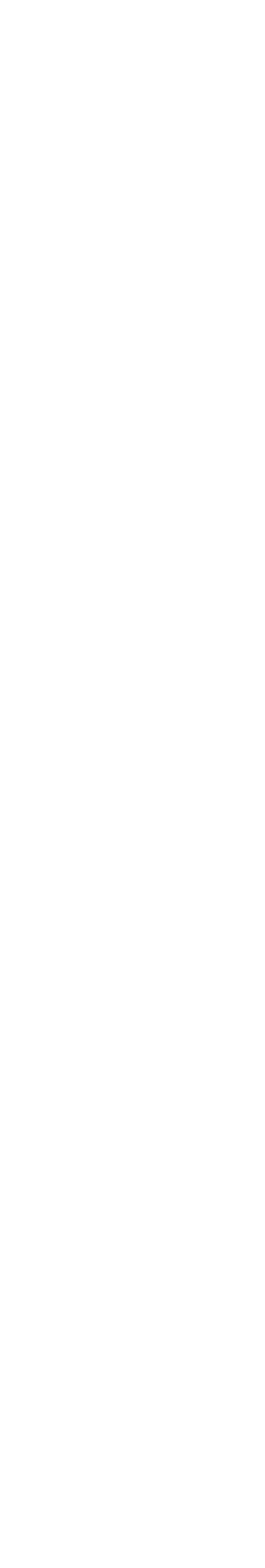

(

.

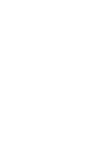



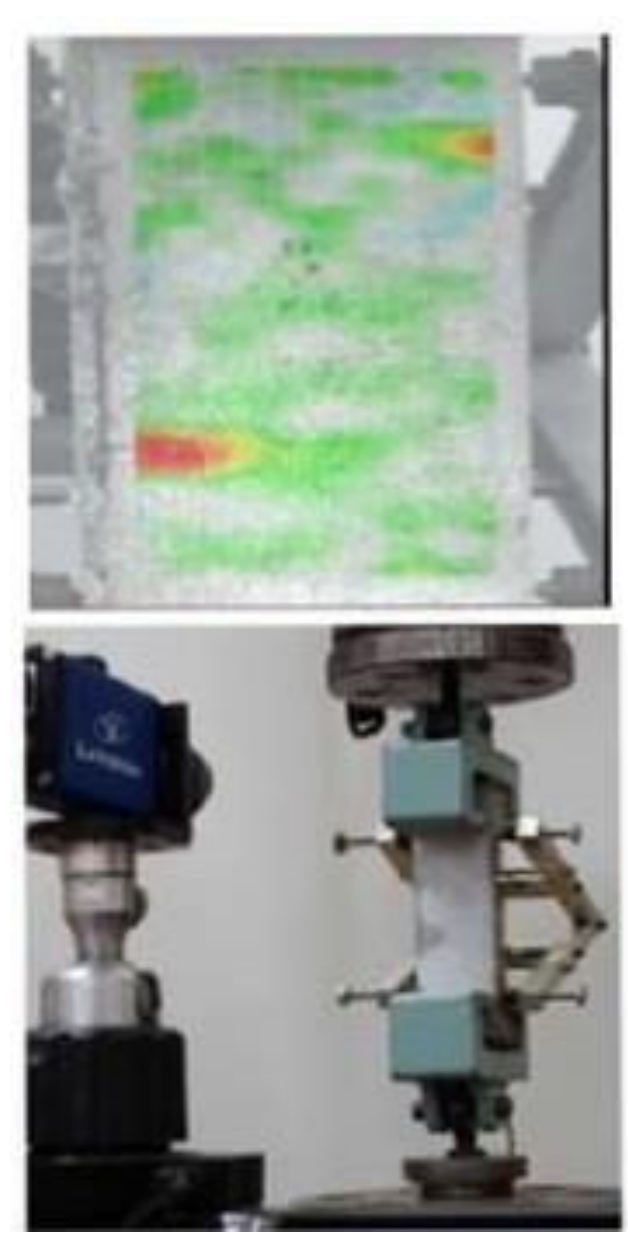
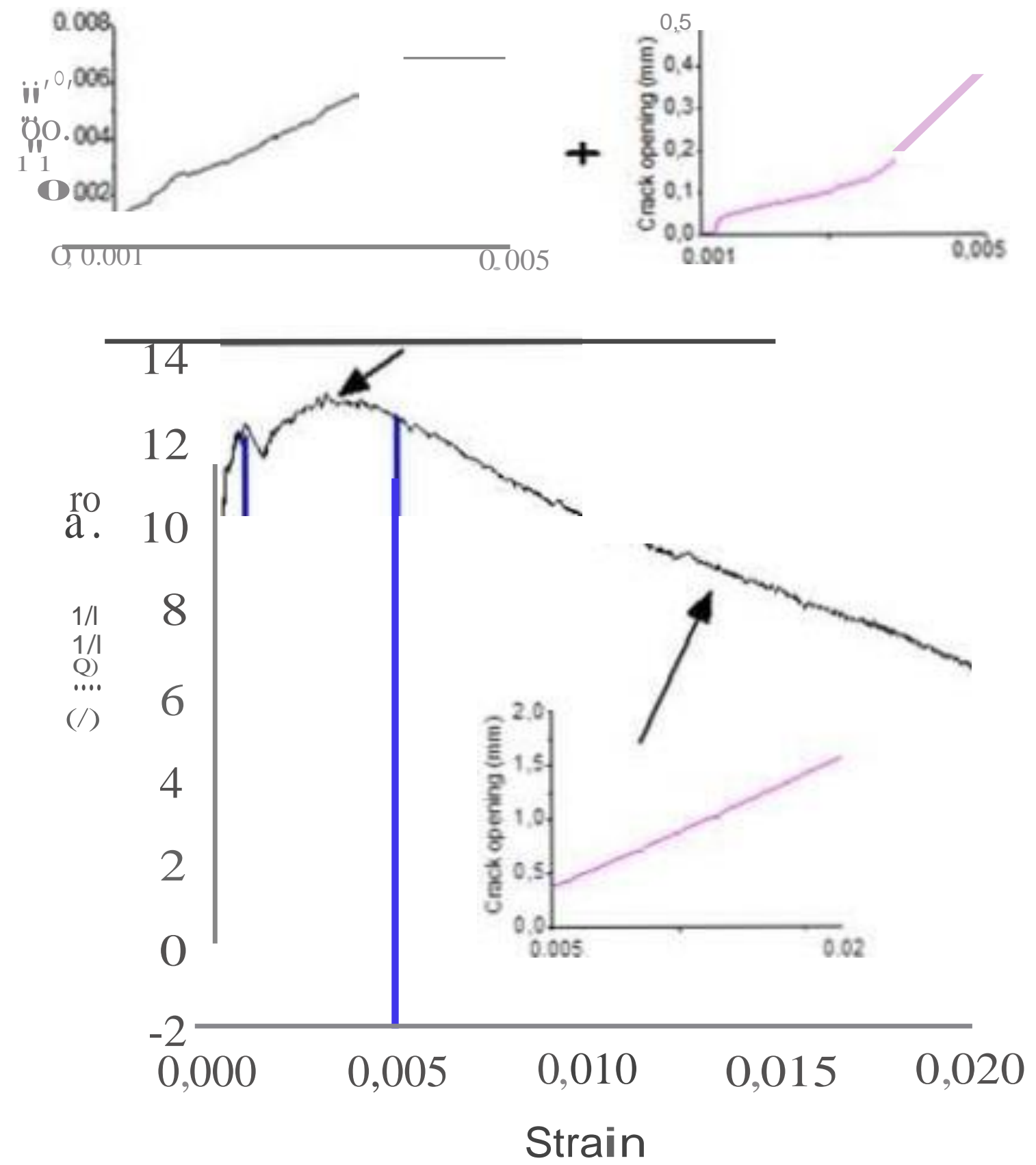

(extension normalised to the total gauge length) 


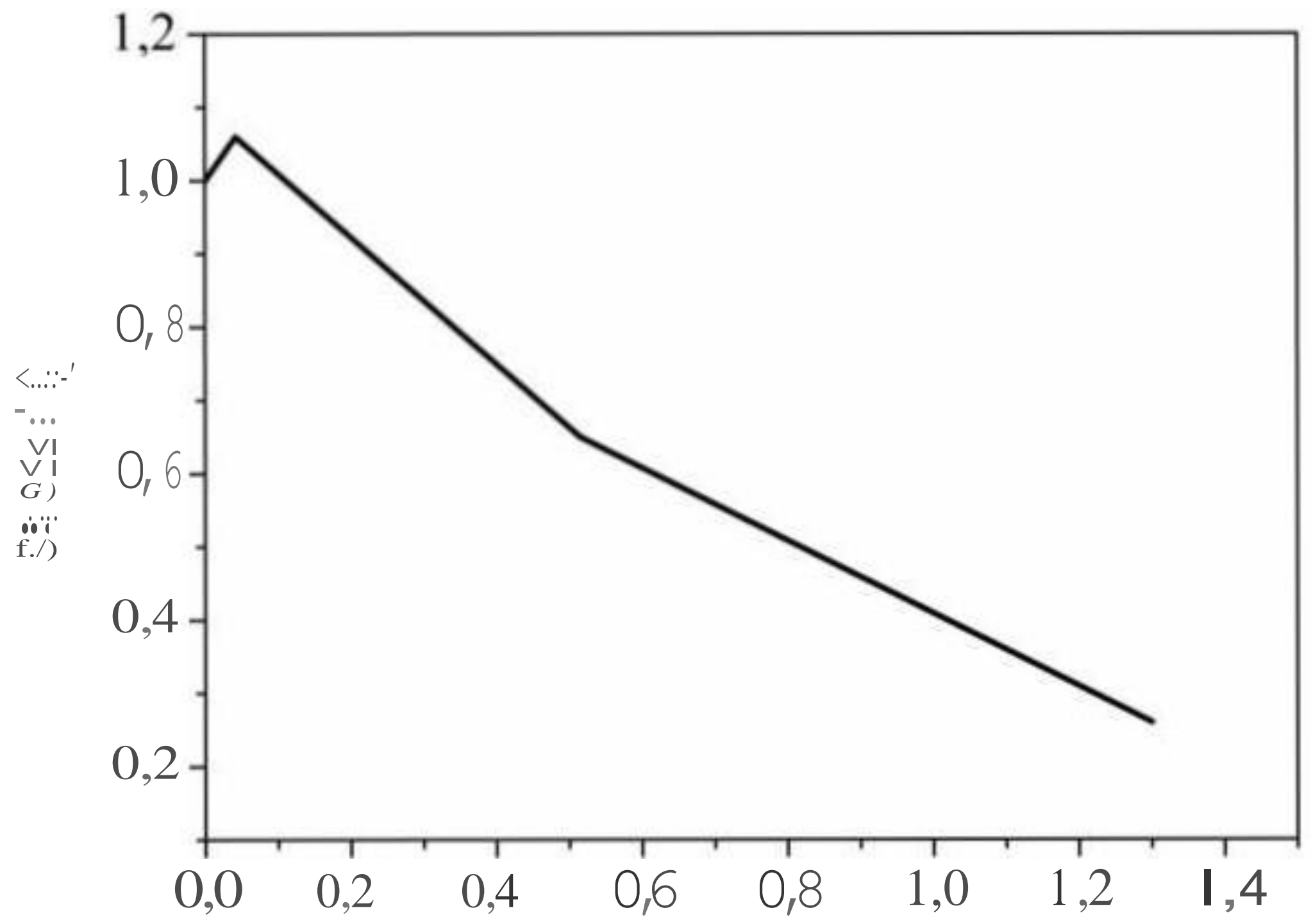

Fracturing strain 


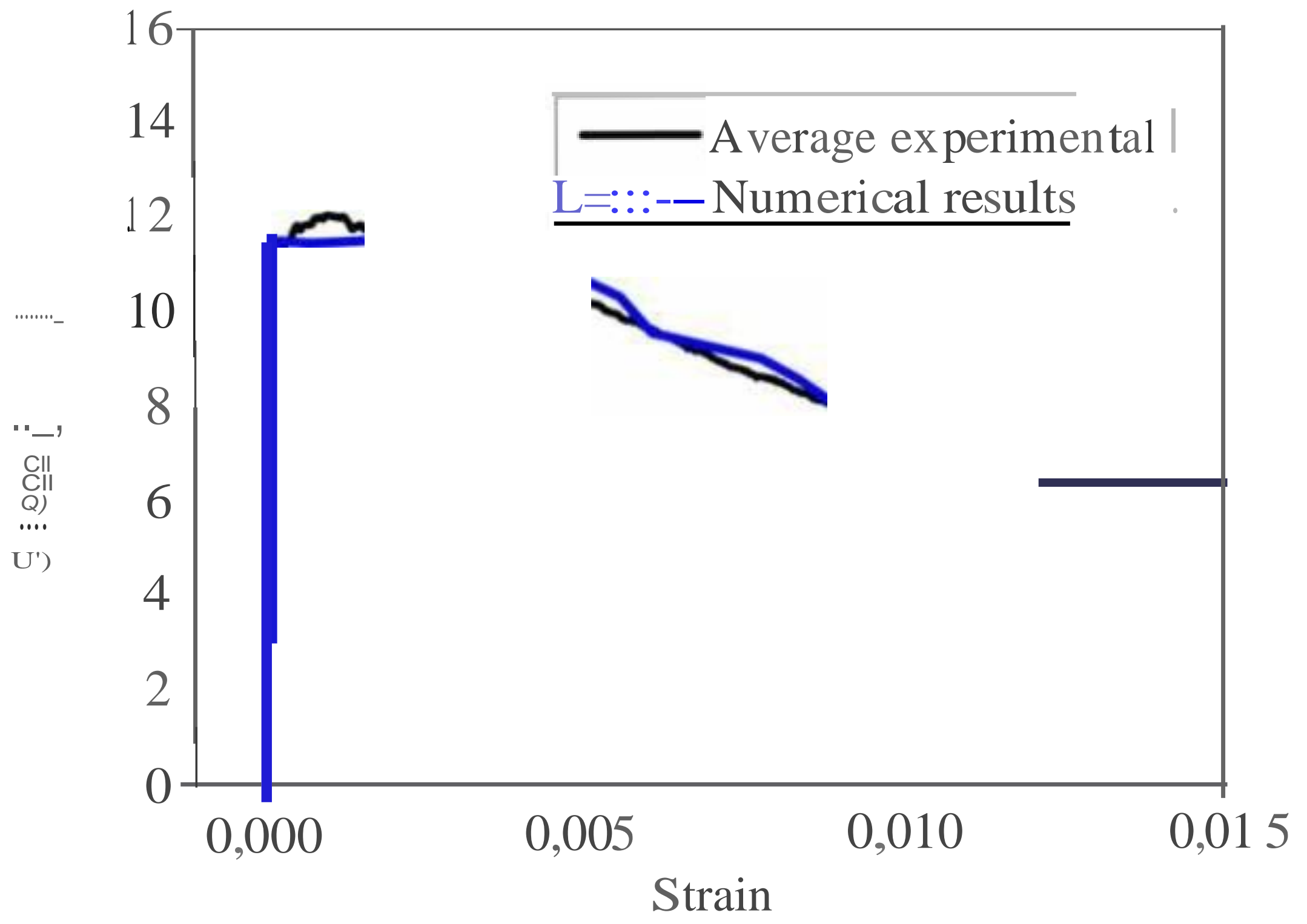




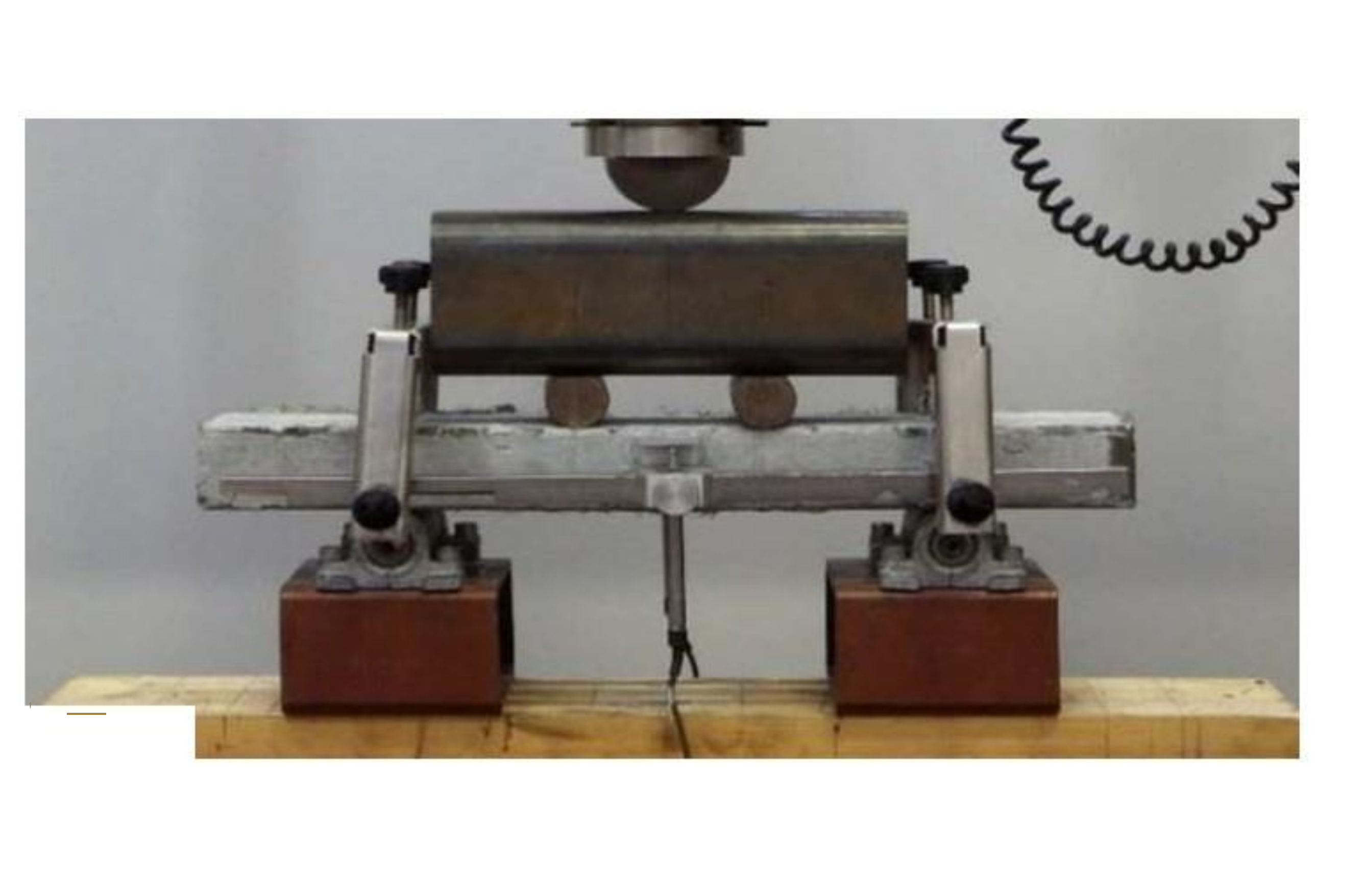

.
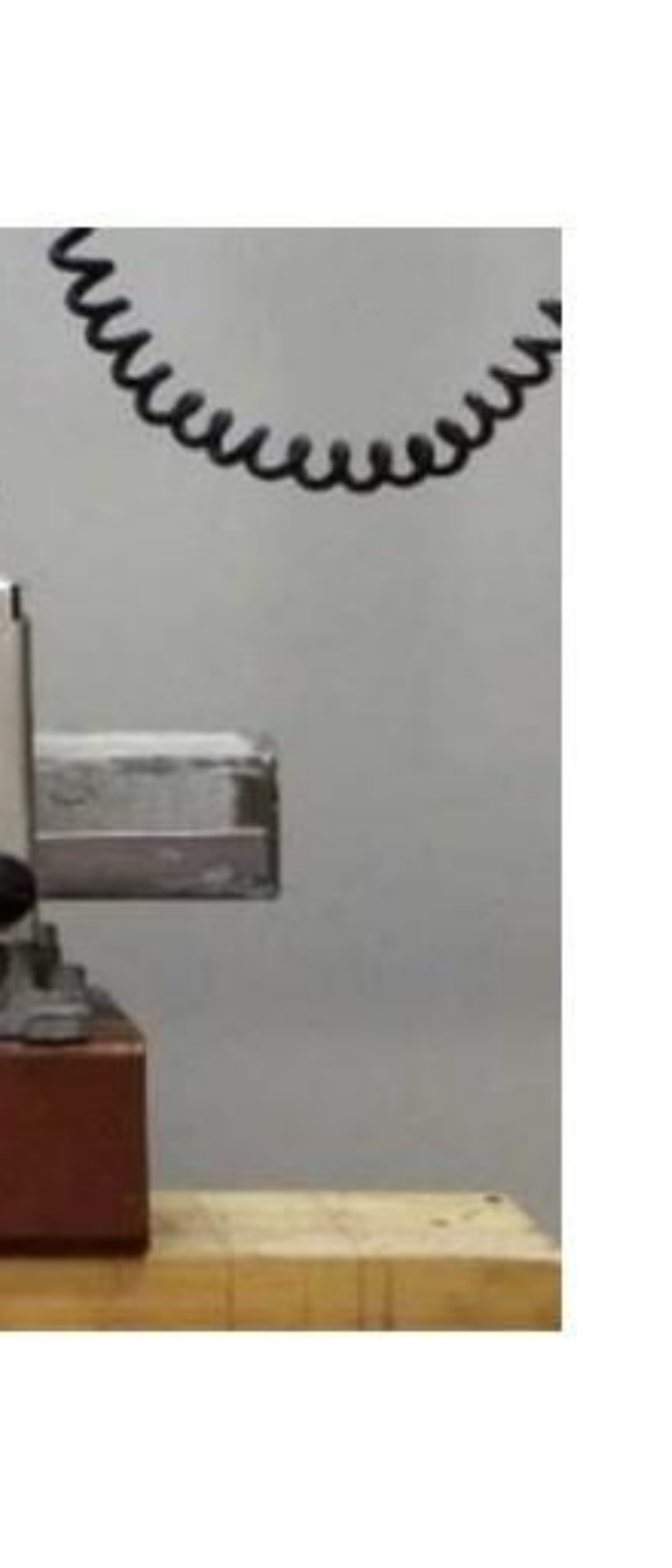


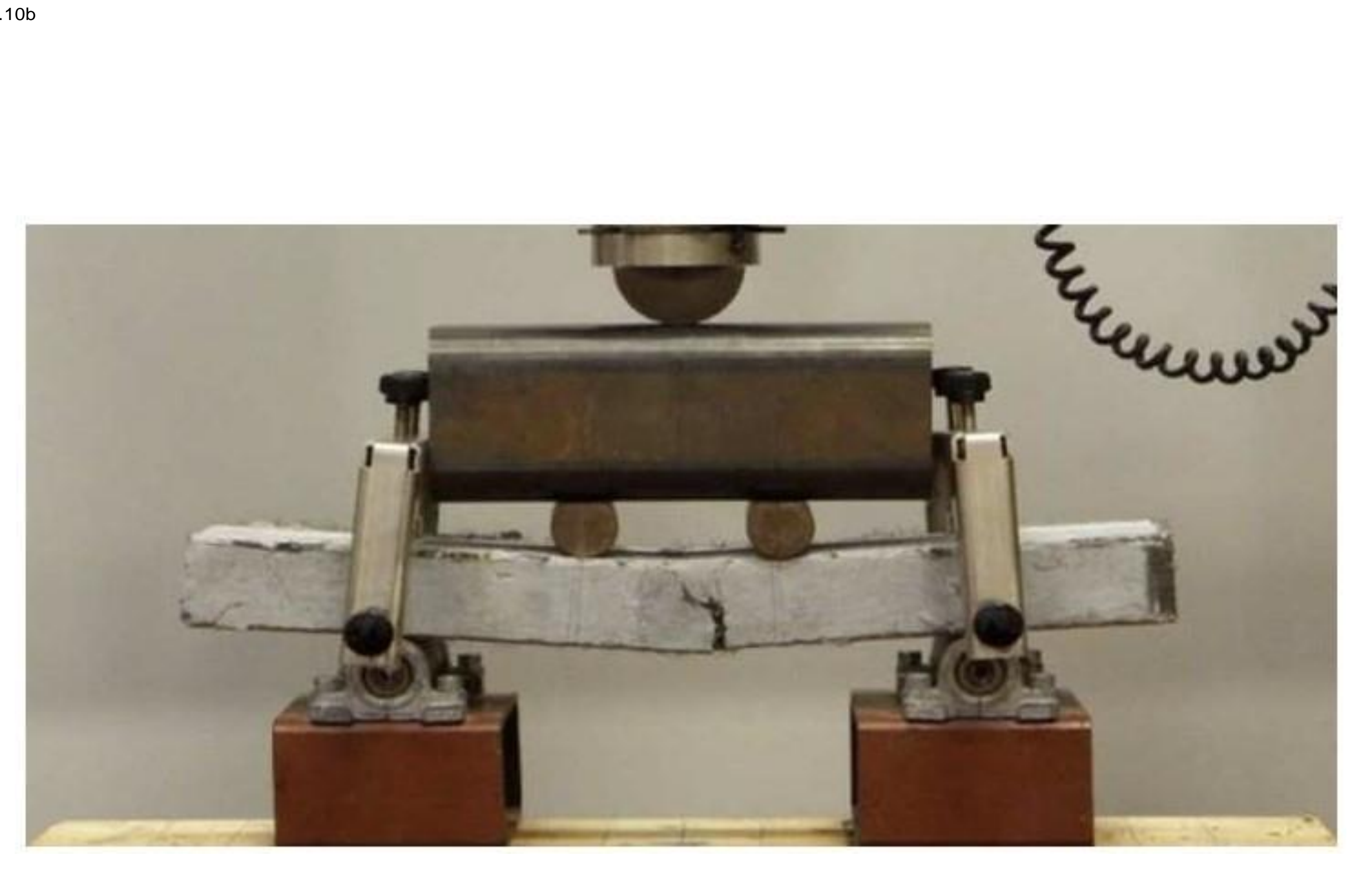

列

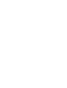

.
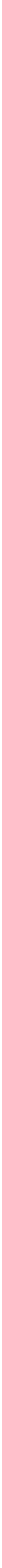


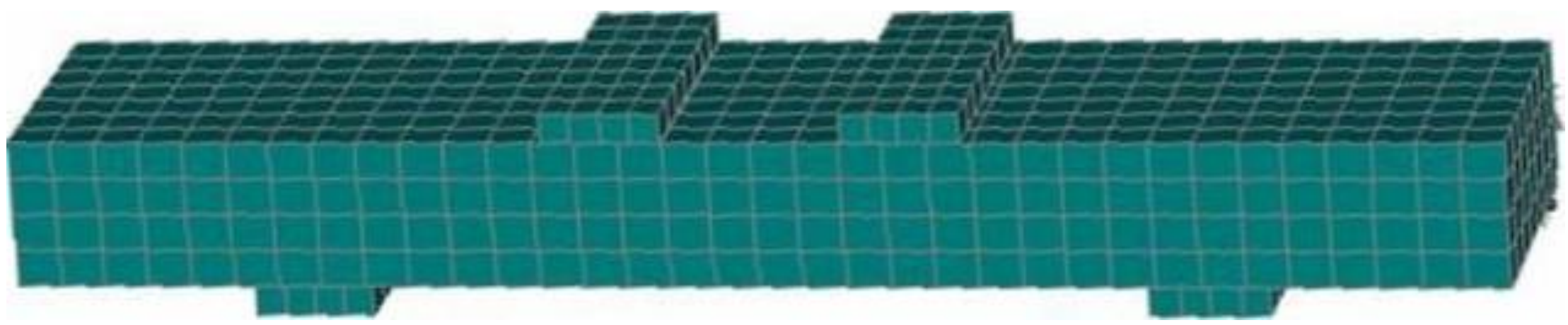




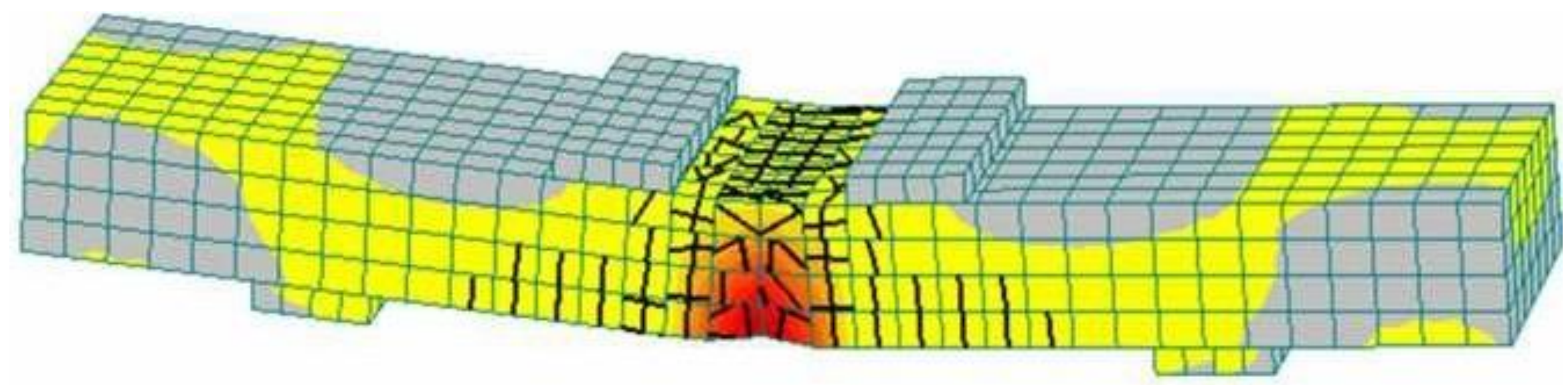




$$
\nu
$$




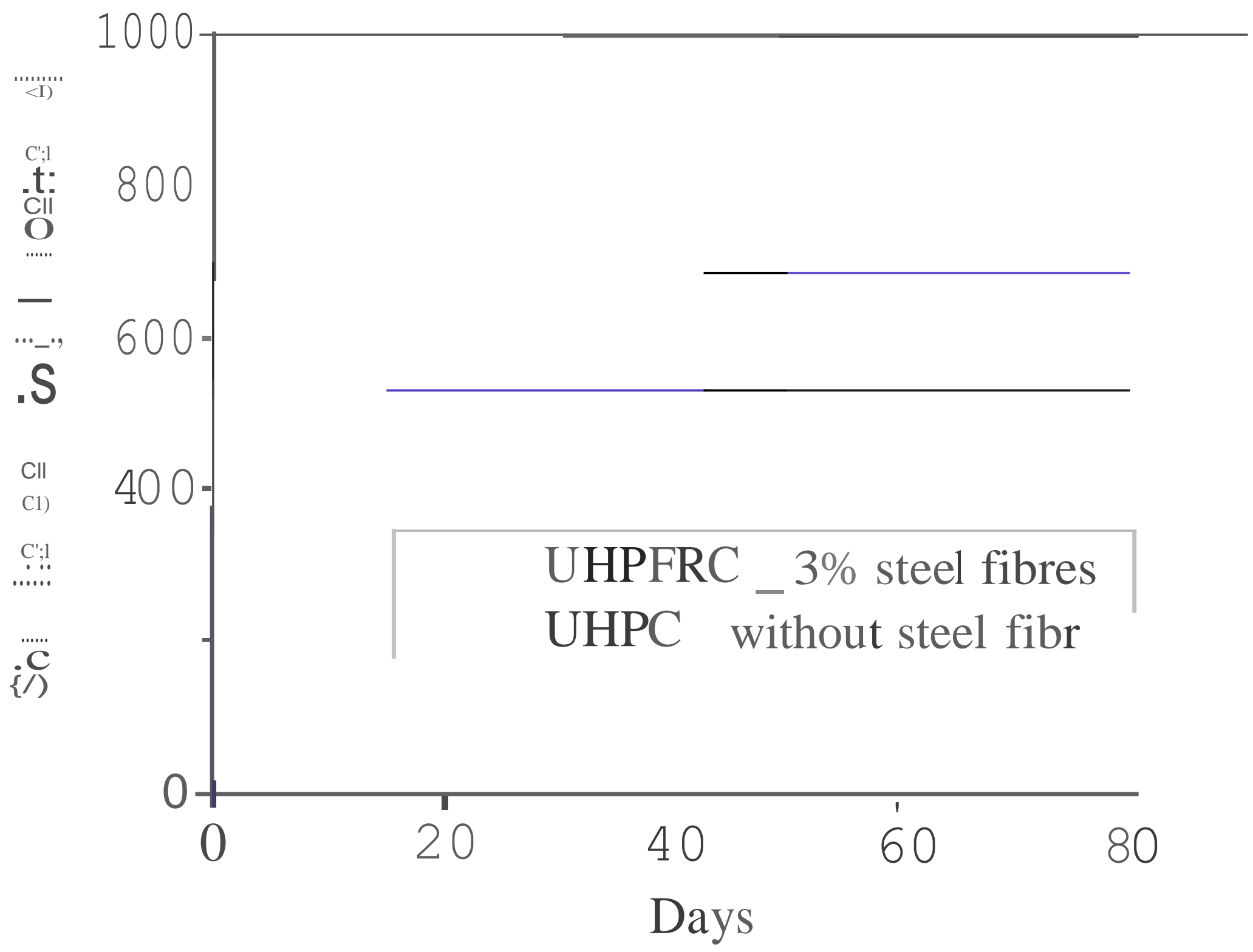



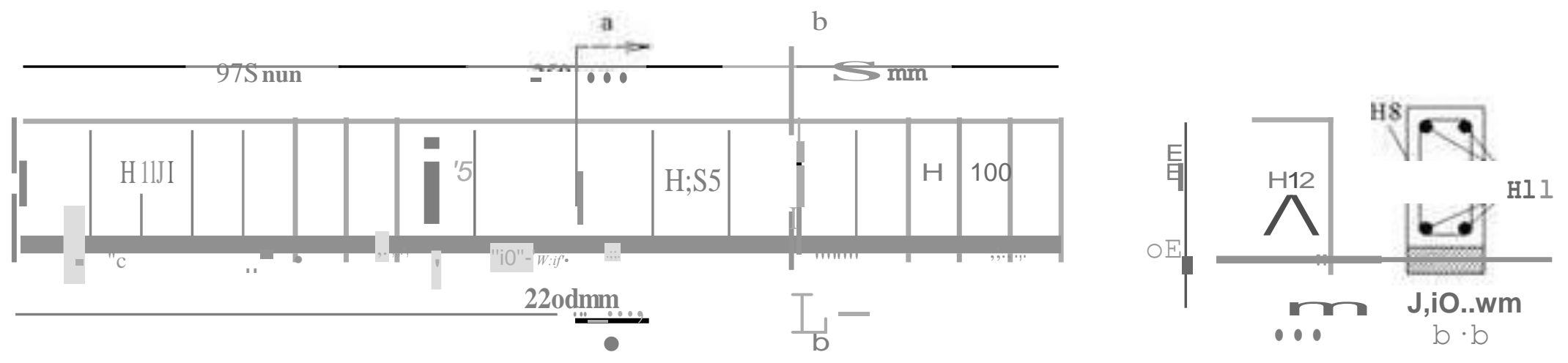


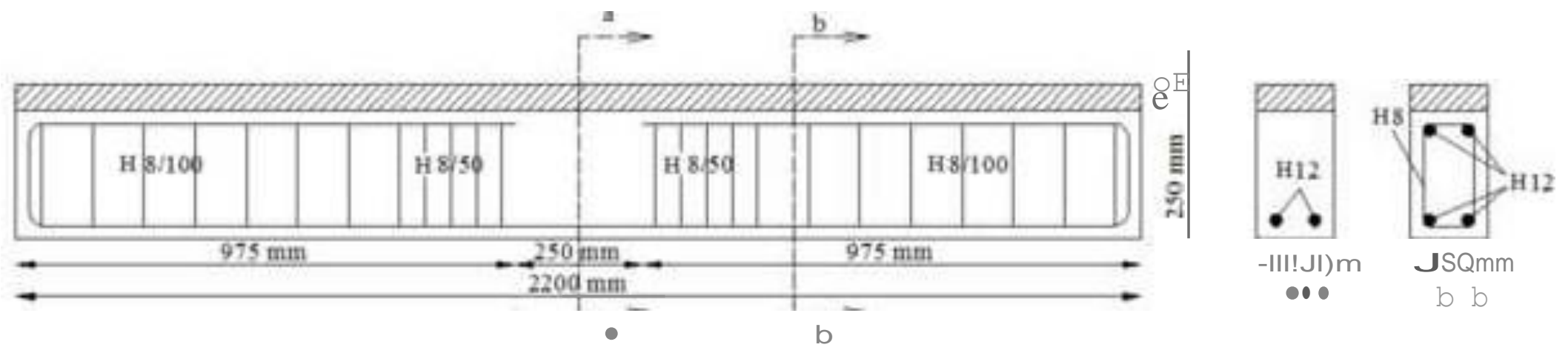




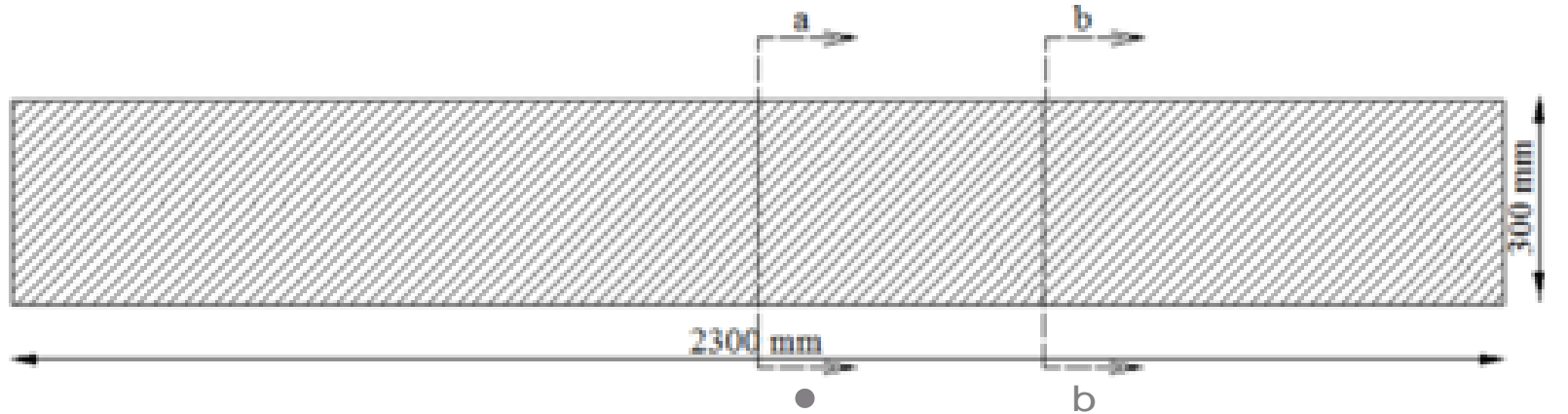

m

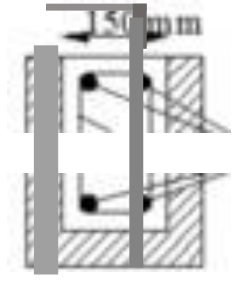

$250 \mathrm{~mm}$

1.50 m.m

$\bullet \quad b-b$ 


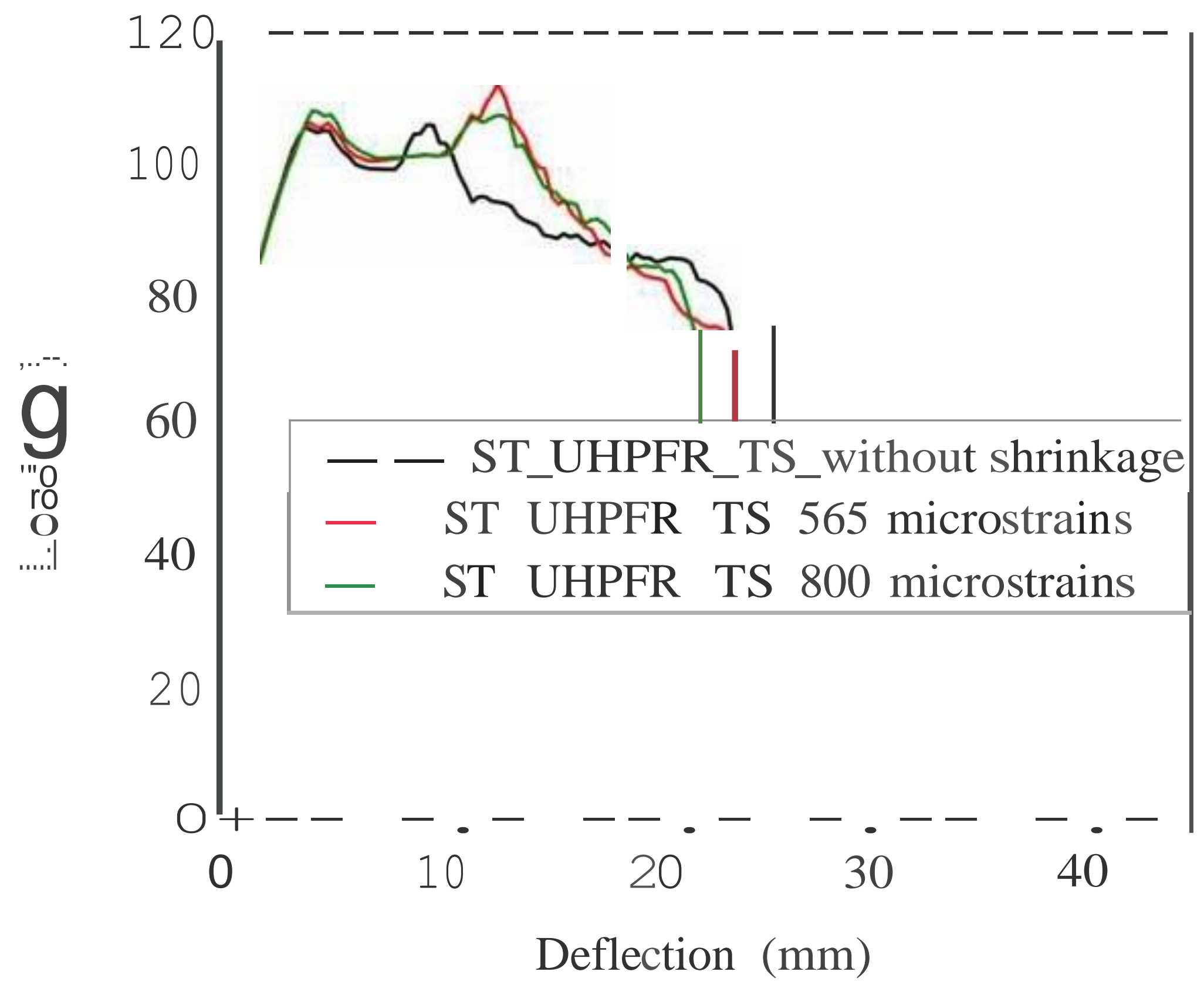




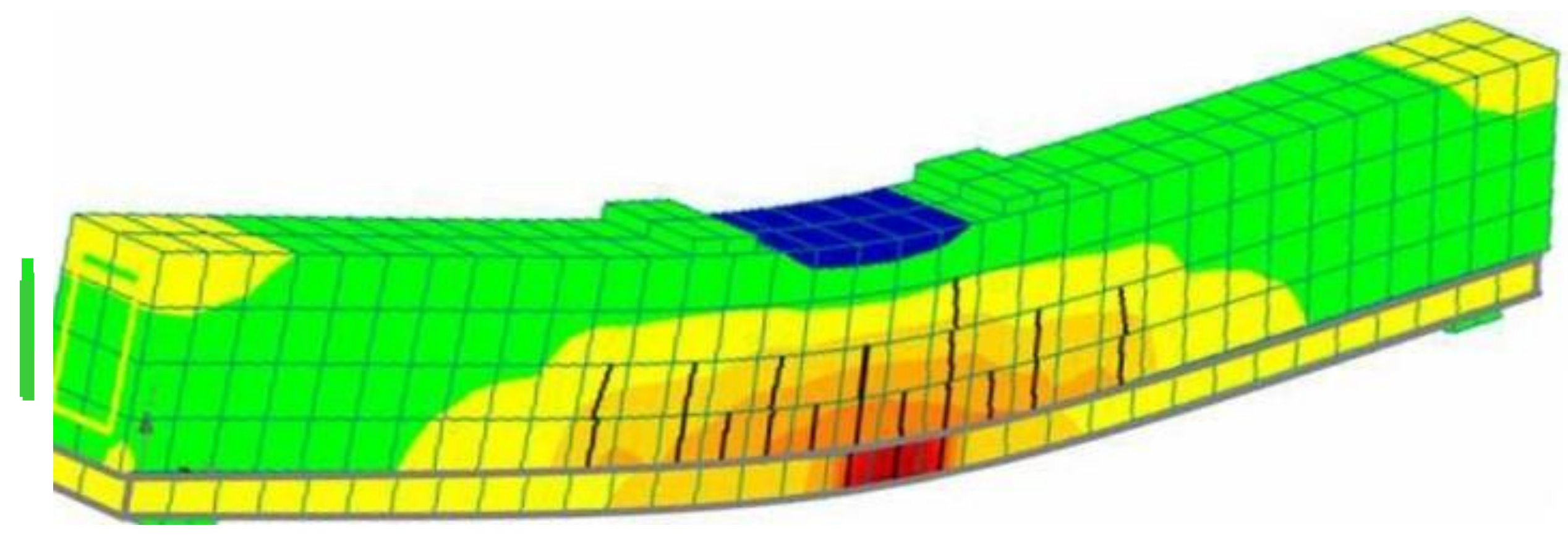



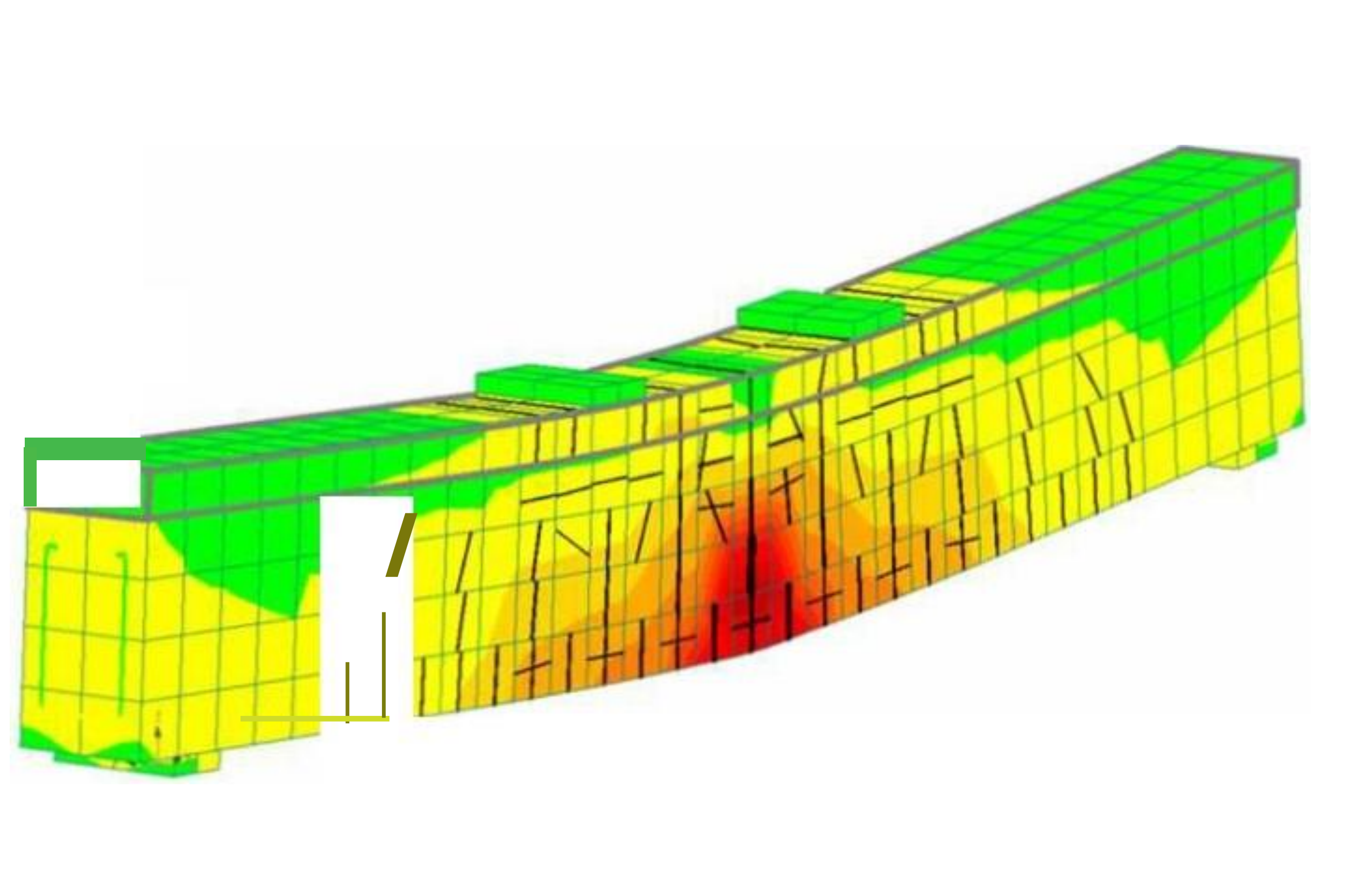


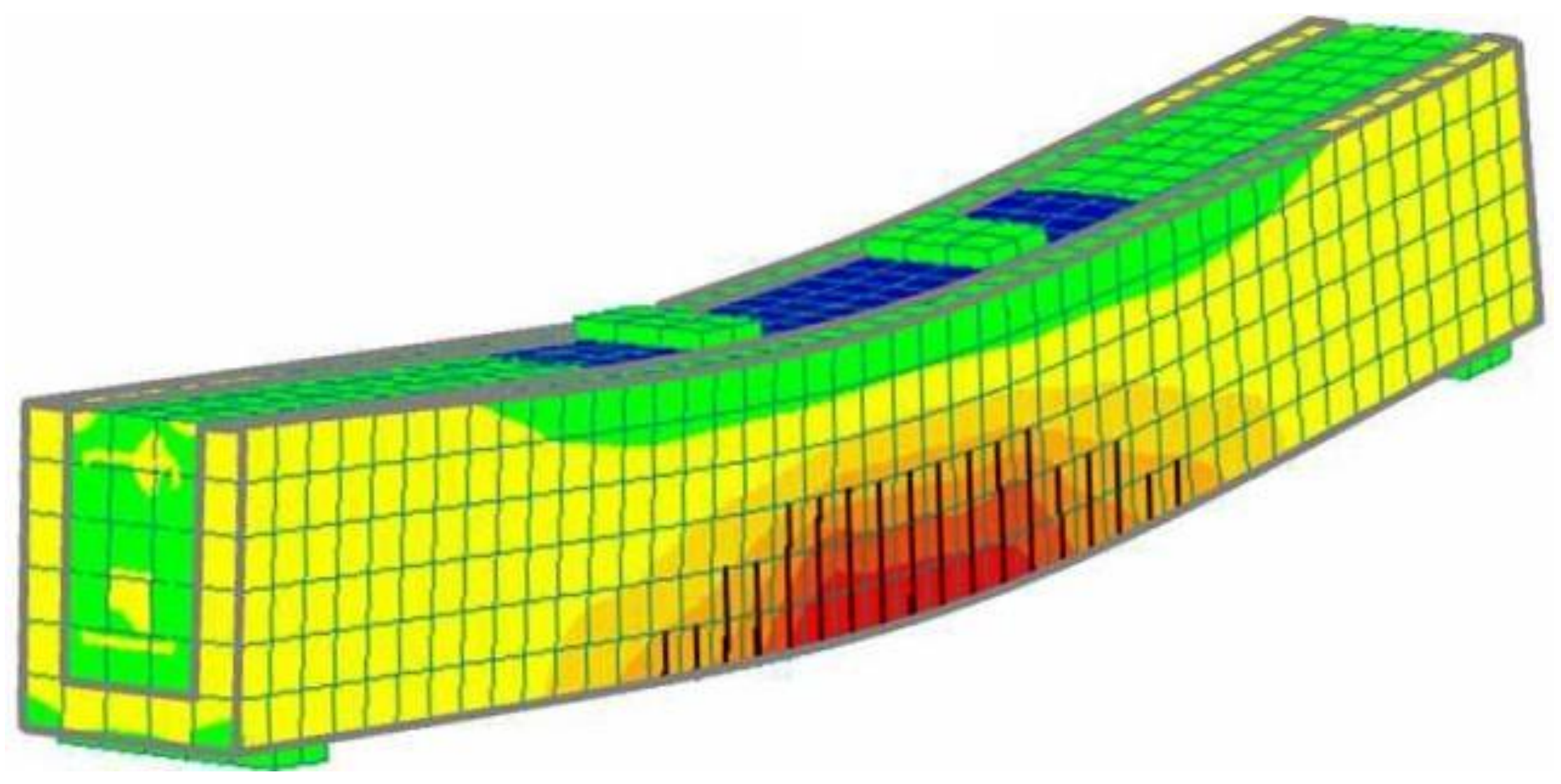




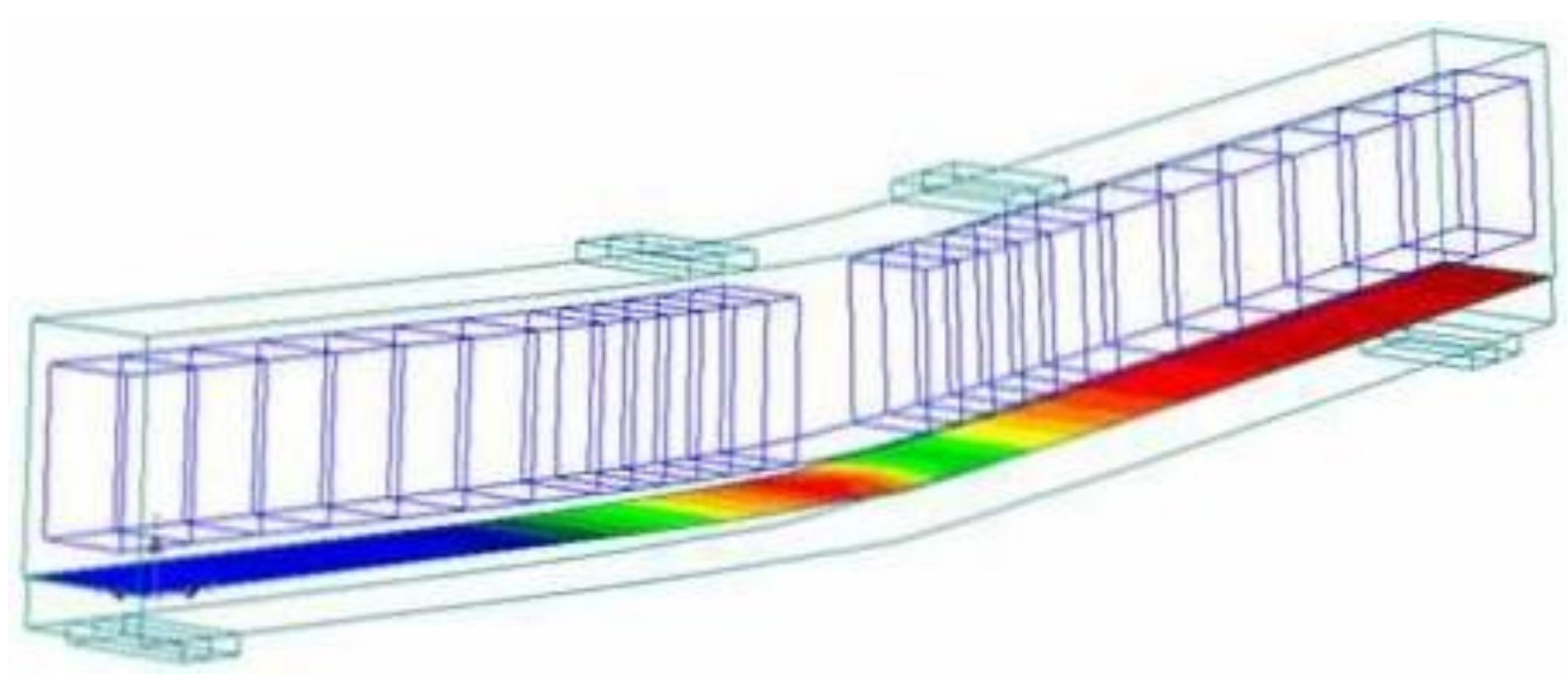

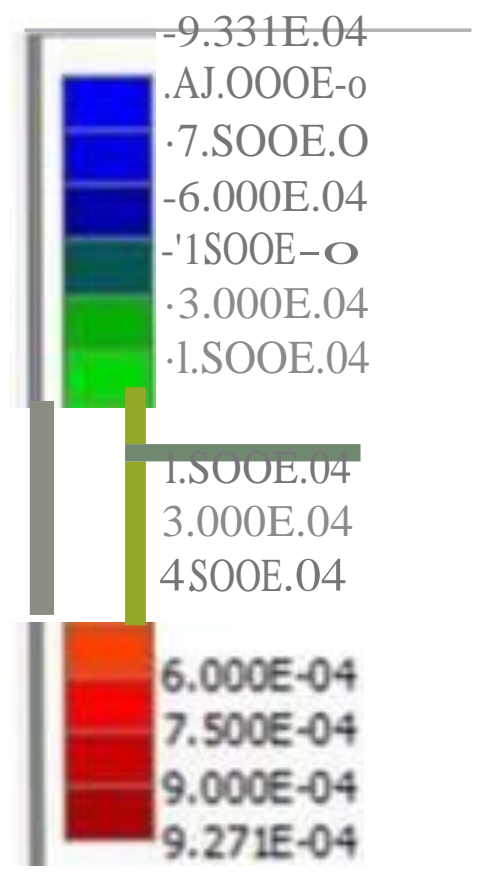




$$
=1
$$




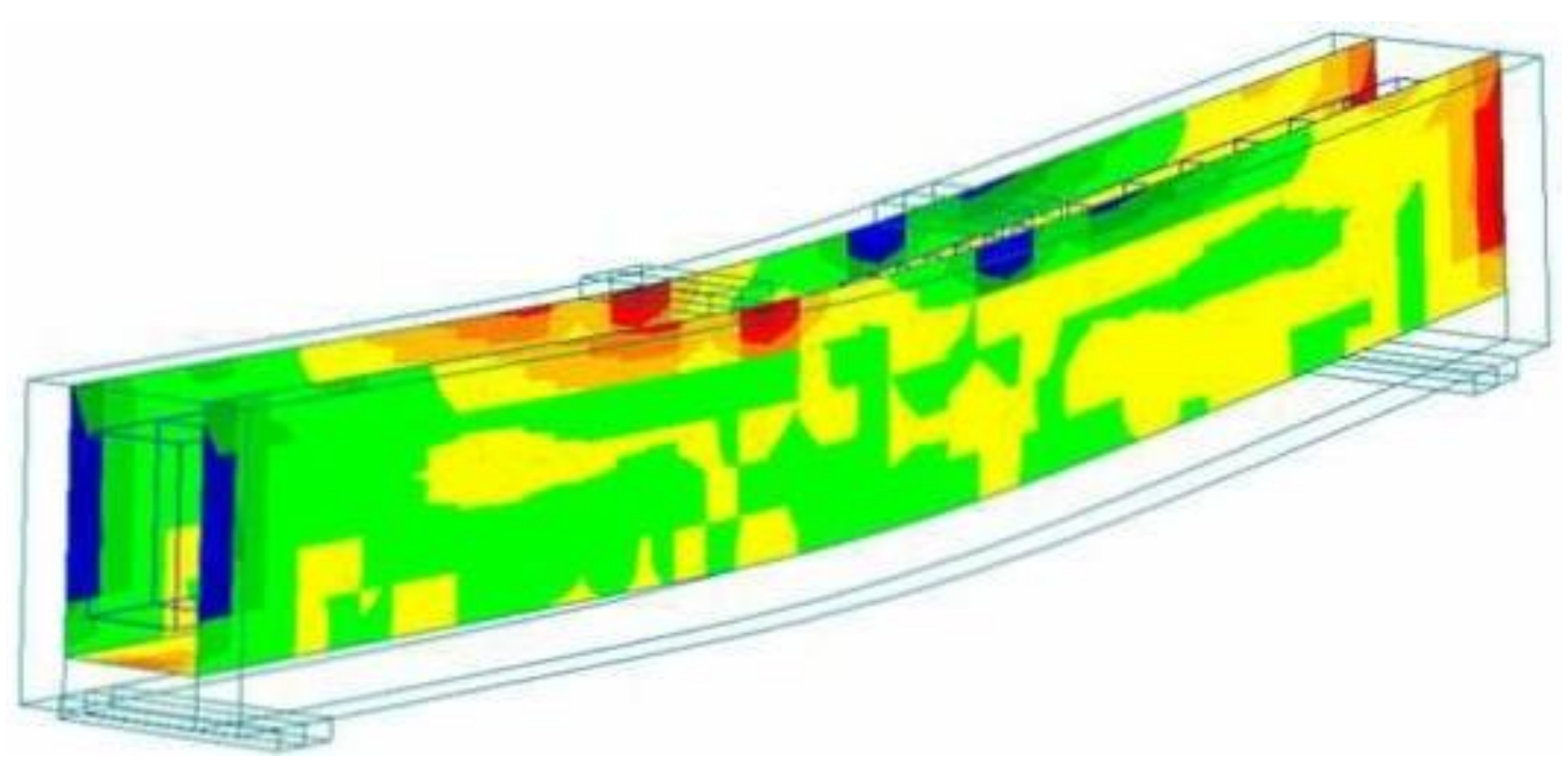

\begin{tabular}{|c|}
\hline $\begin{array}{l}\cdot 5.3941: 5 \\
-4.500 E 5 \\
\cdot 3.600 E 5 \\
\cdot 2.700 E ~ S \\
\cdot 1 . S O O E ~ S \\
-9.000 E 6 \\
0.000 E+0 C \\
9.000 E-06 \\
1 . S O O E S \\
2.700 E S \\
3.600 E 5 \\
4 . S O O E S \\
5.298 E S\end{array}$ \\
\hline
\end{tabular}




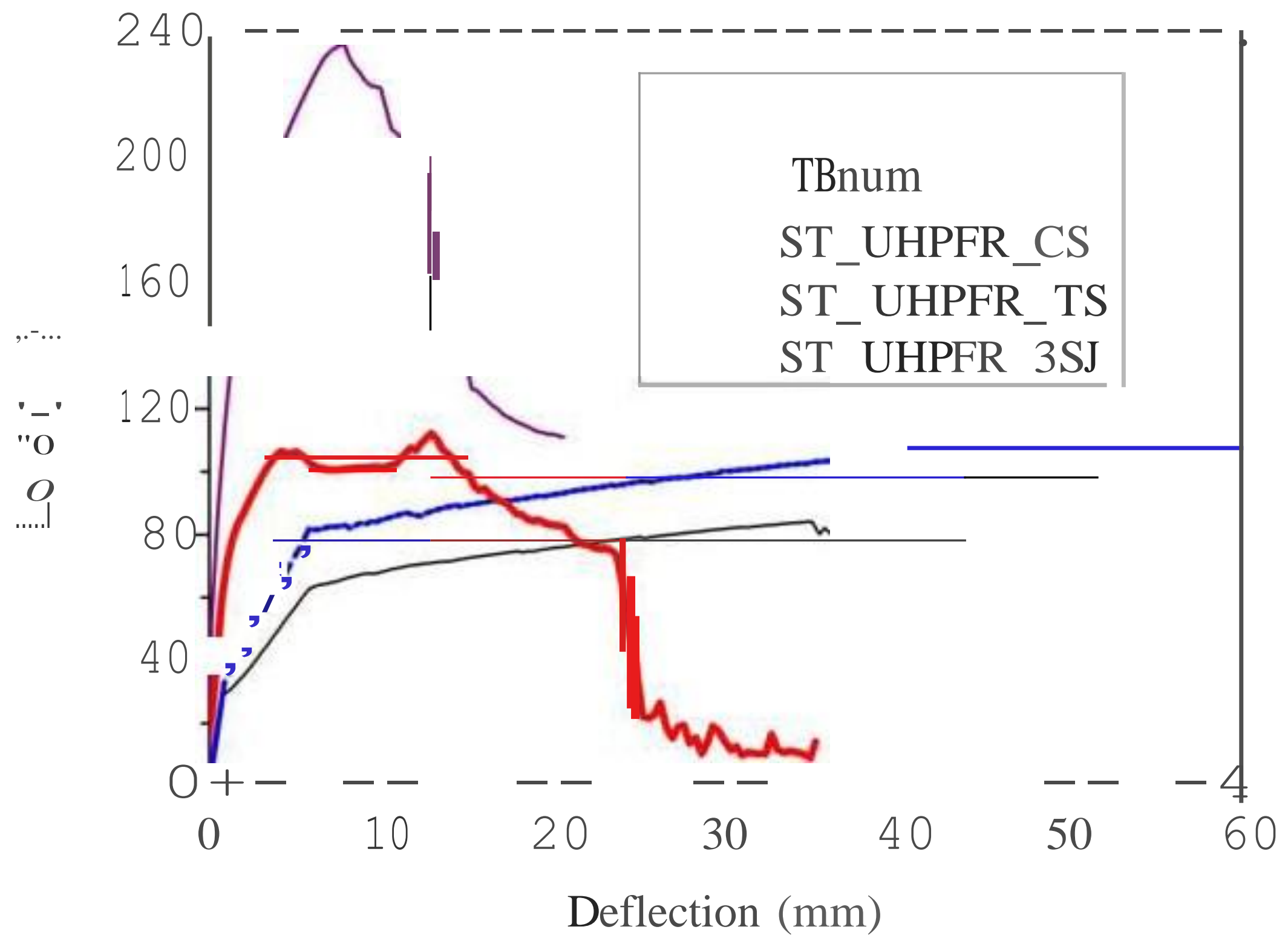




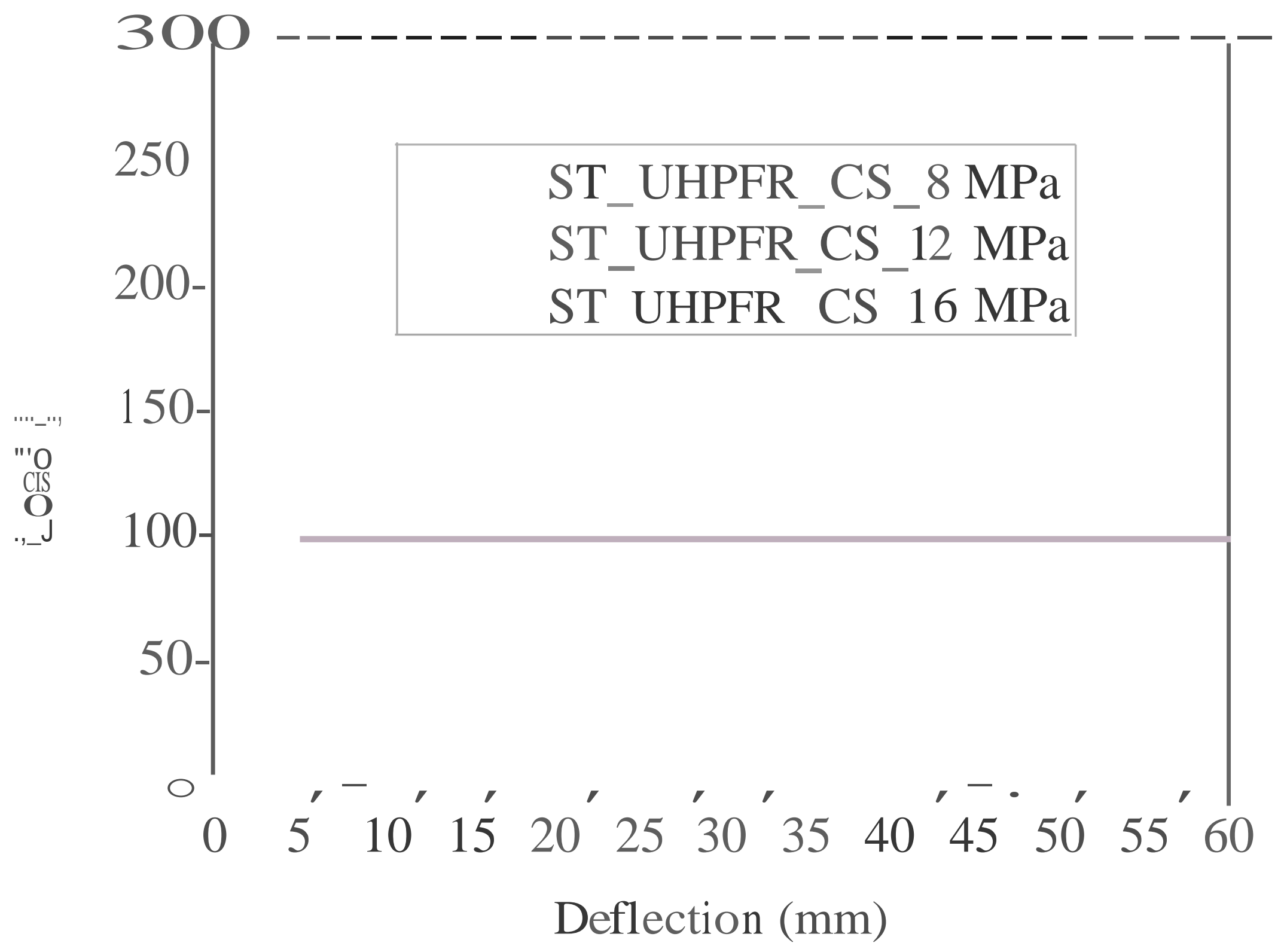




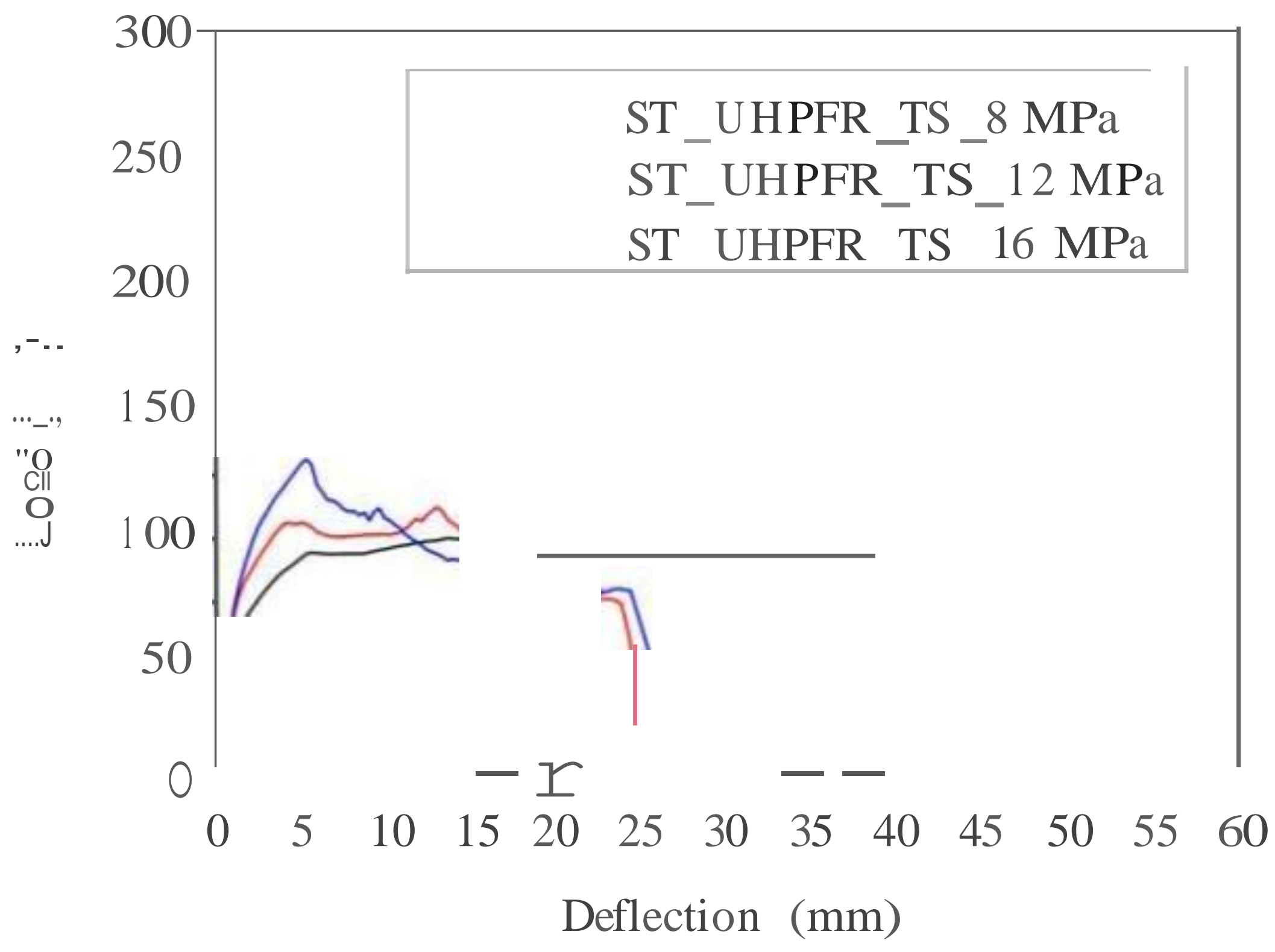




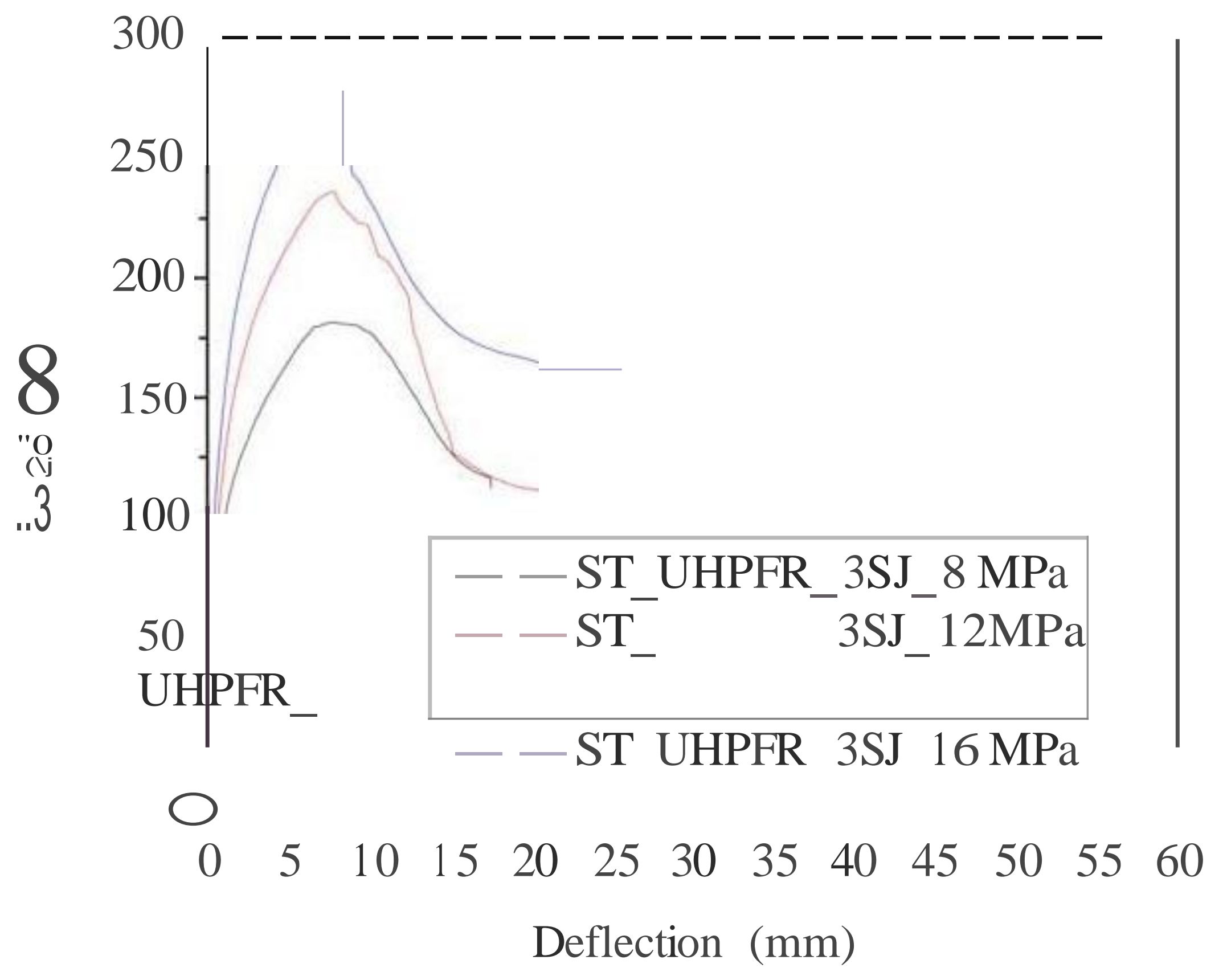




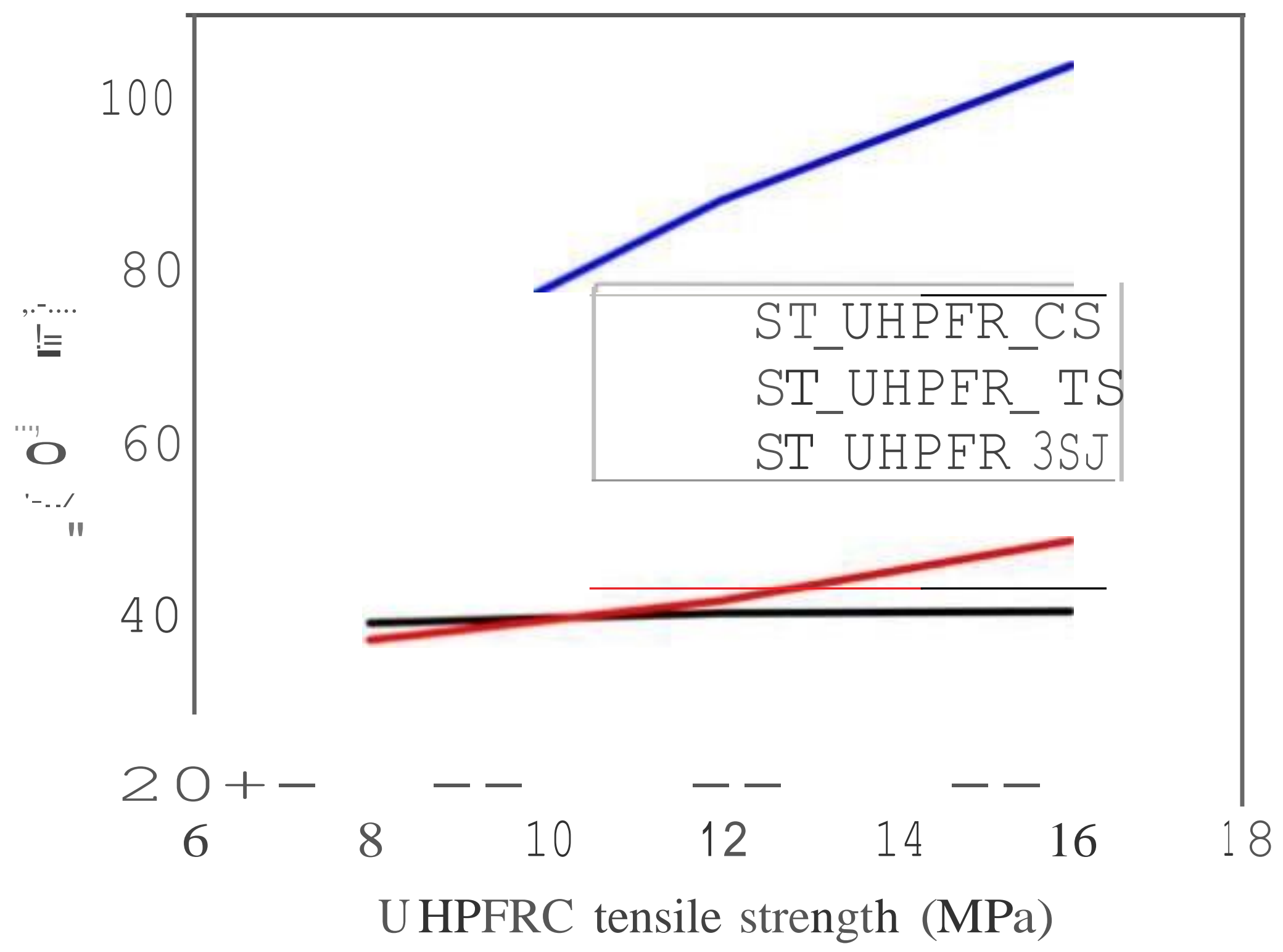




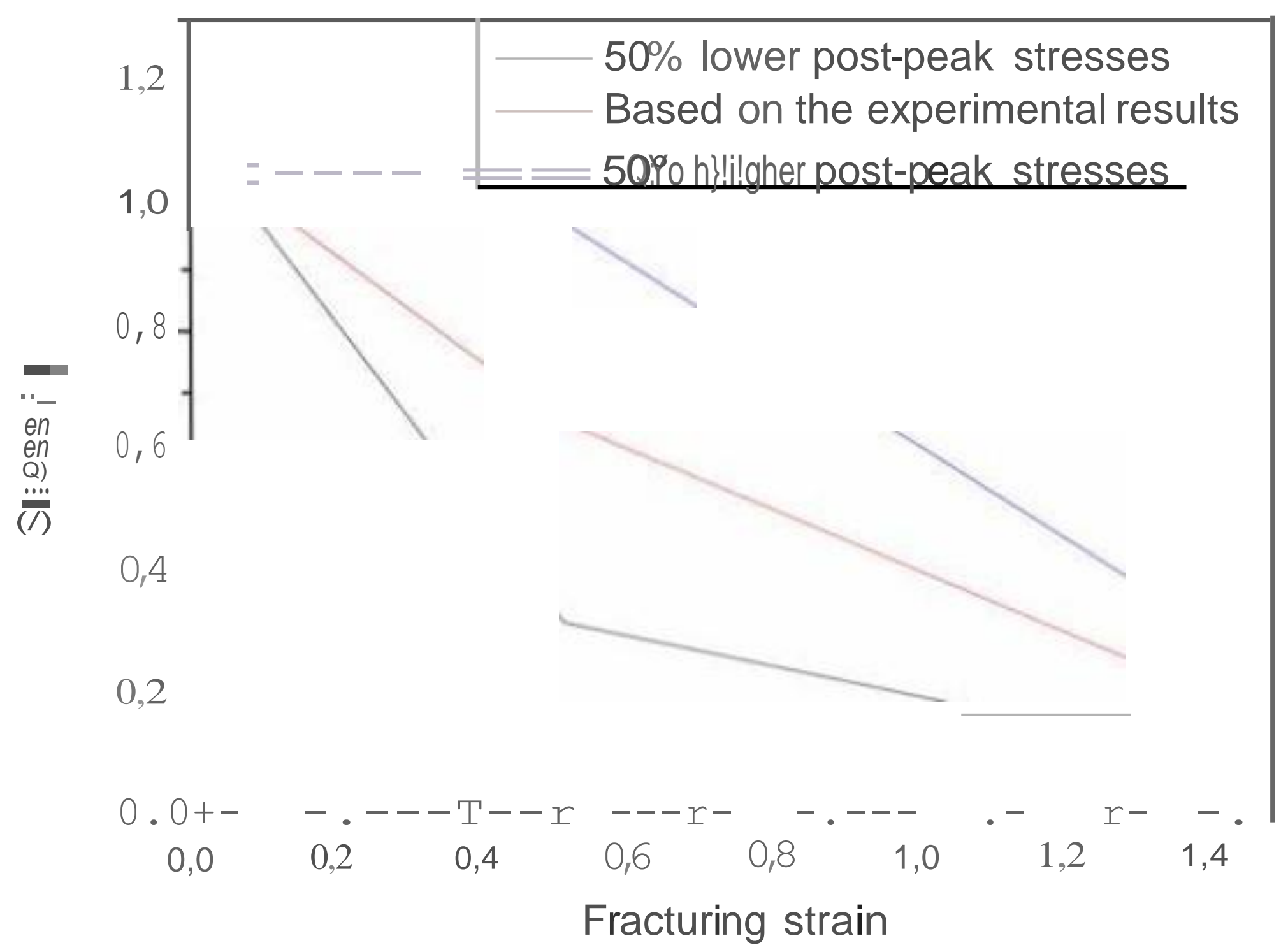




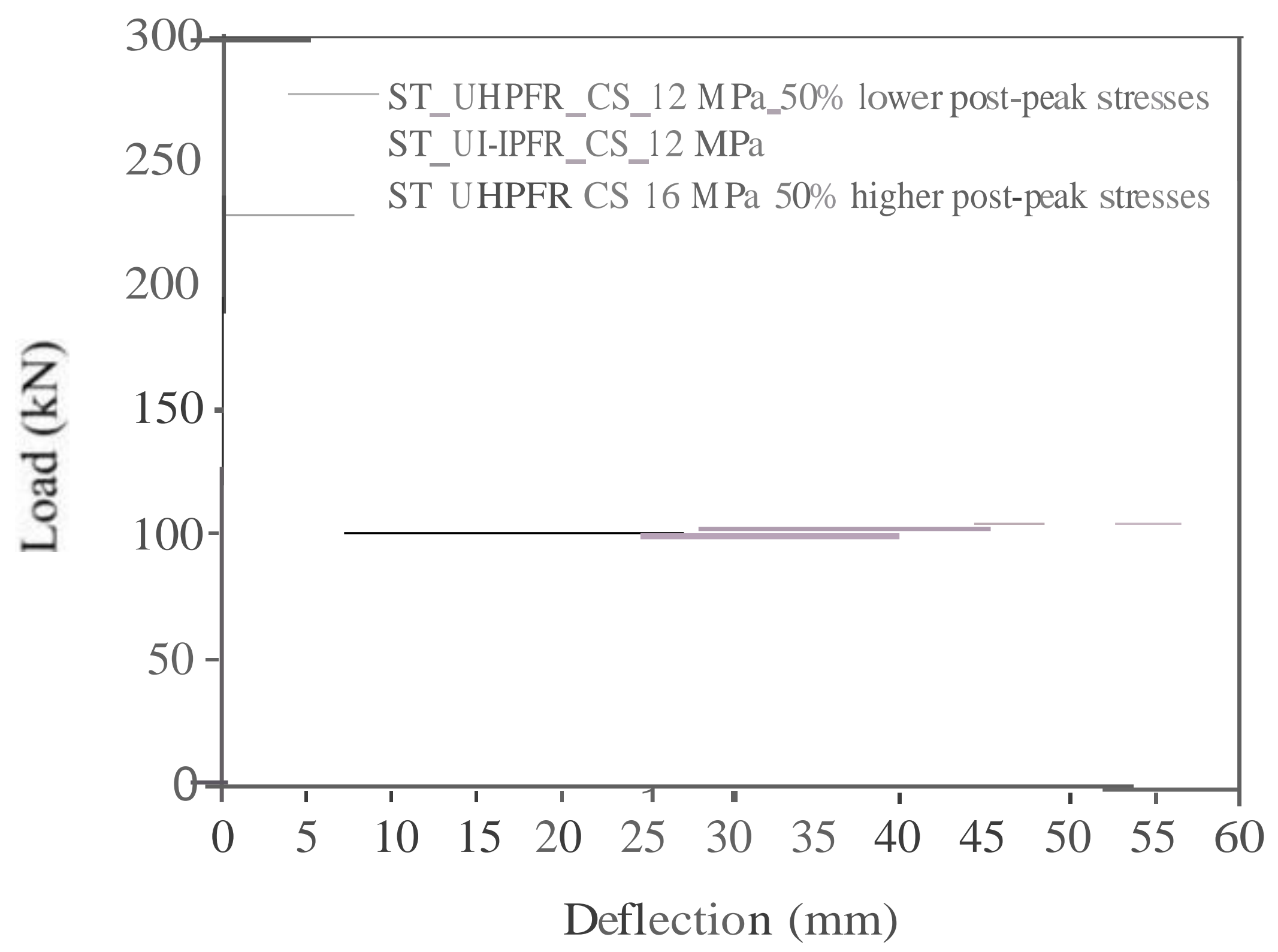




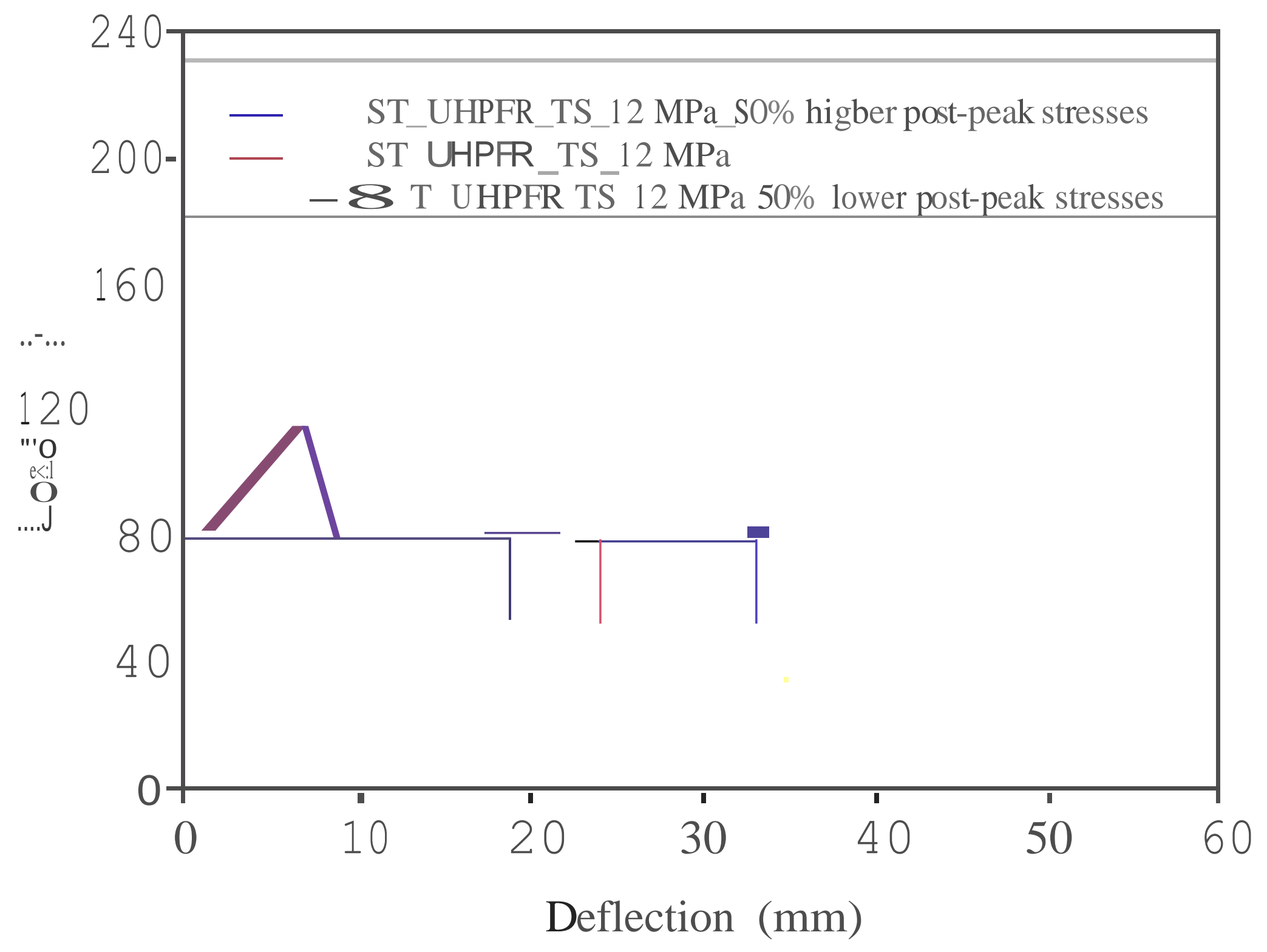




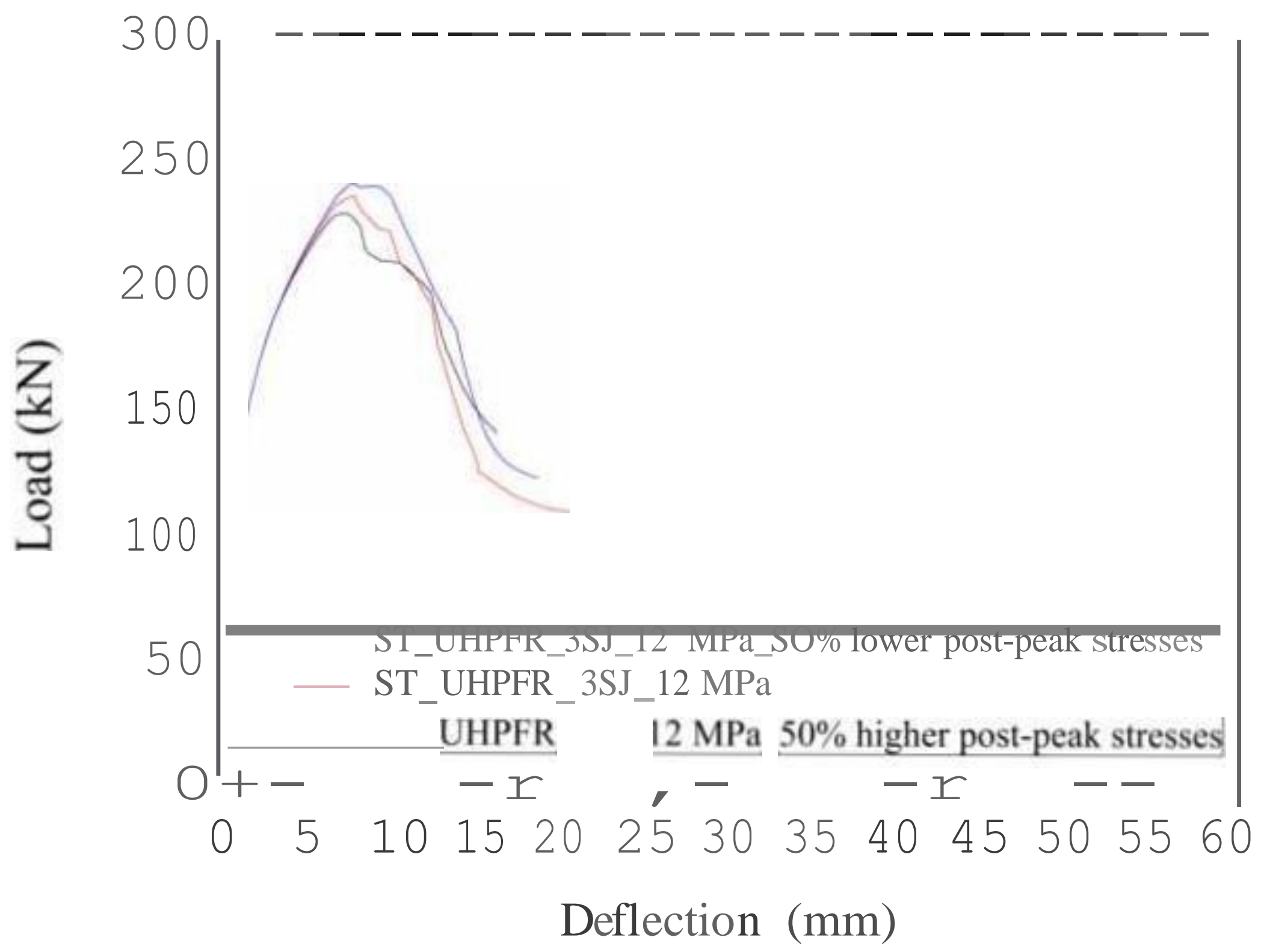




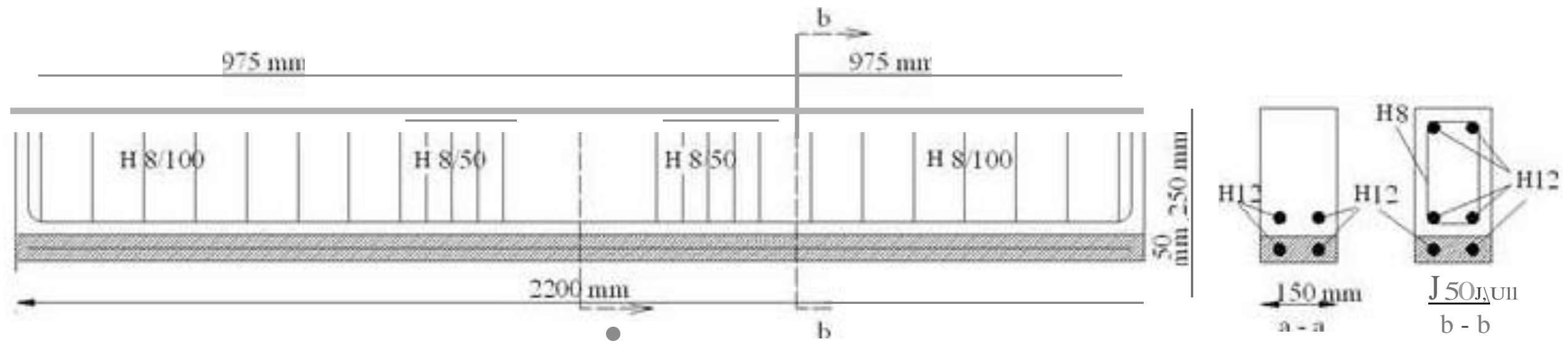




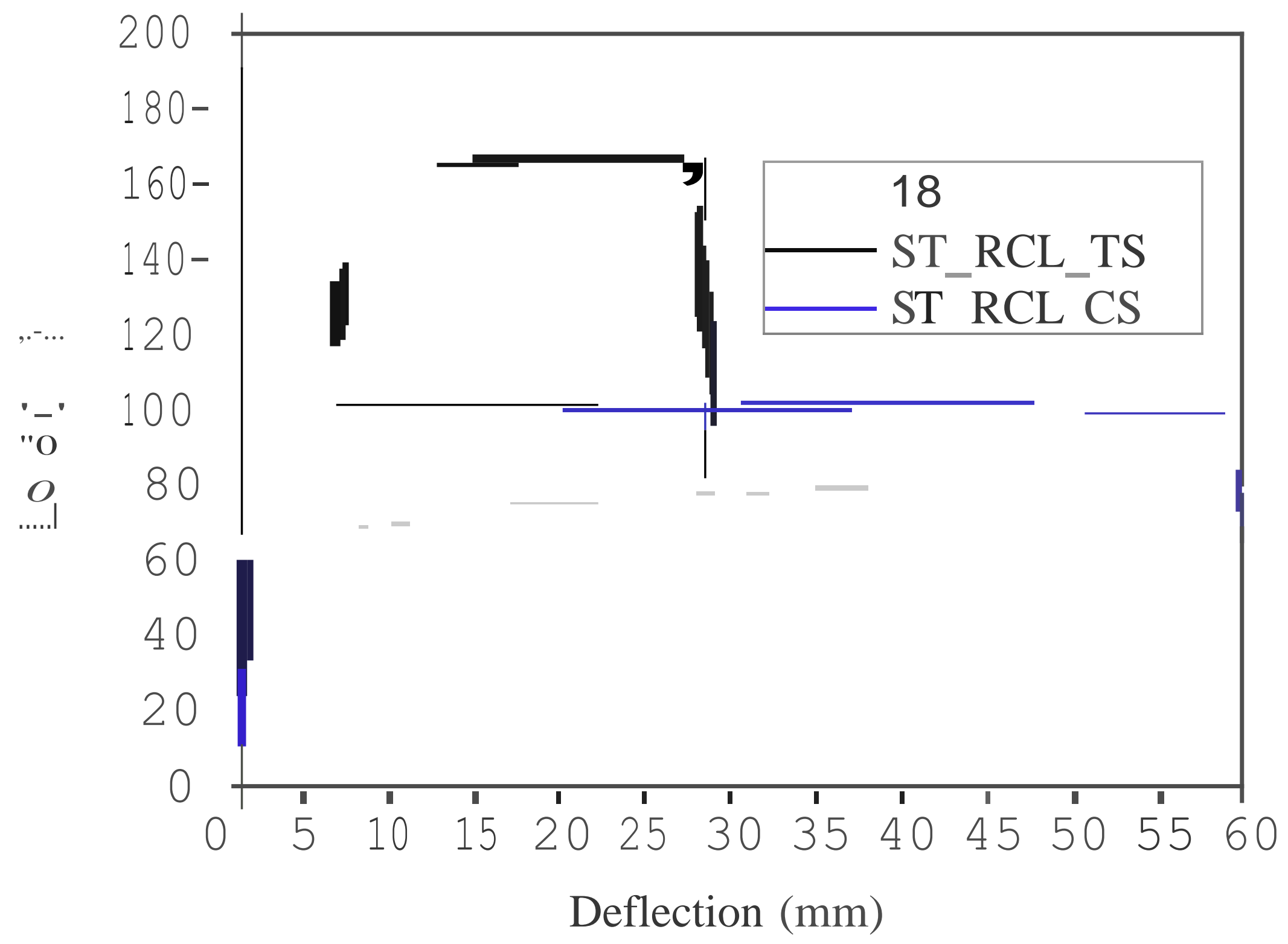




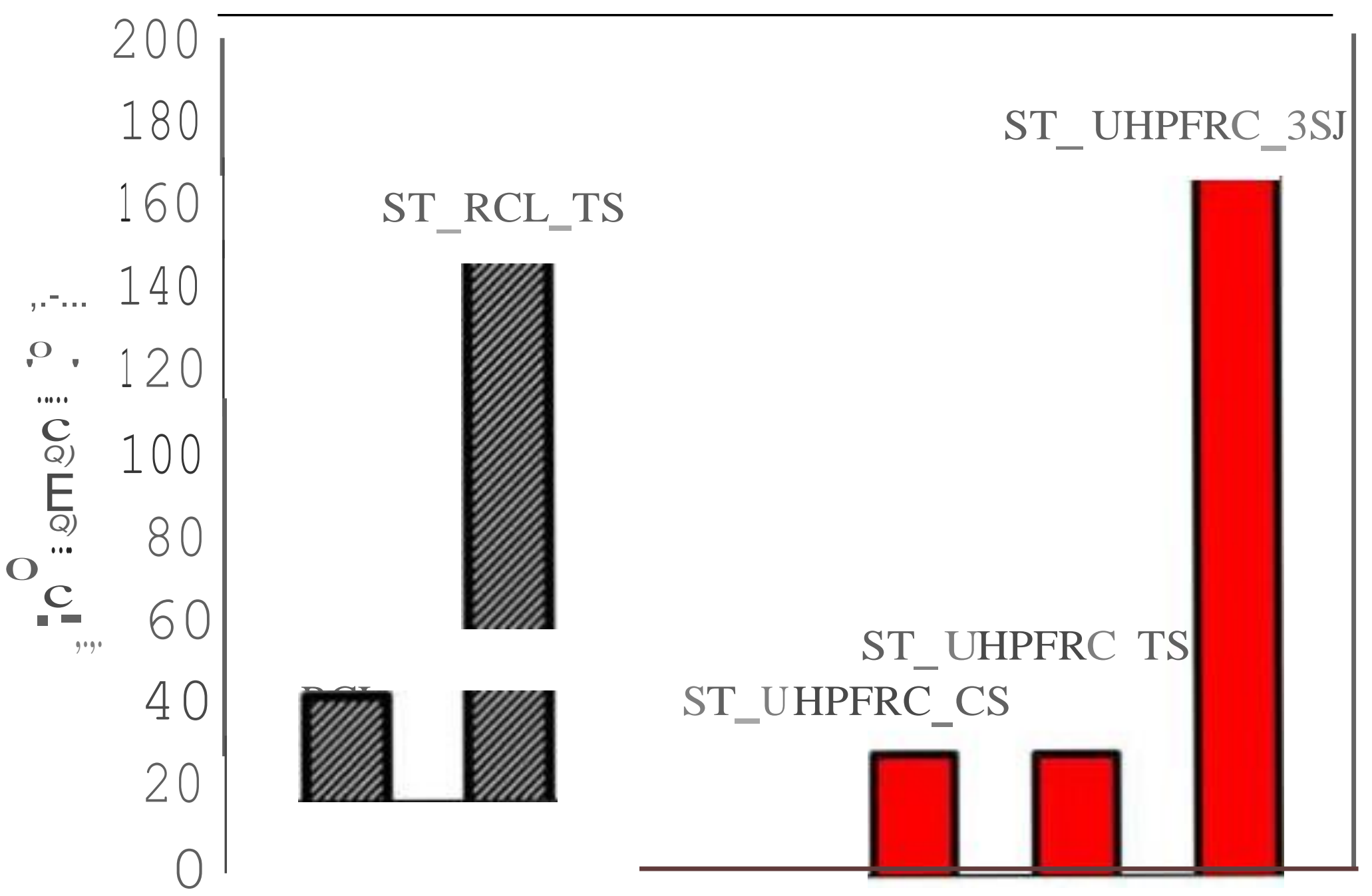




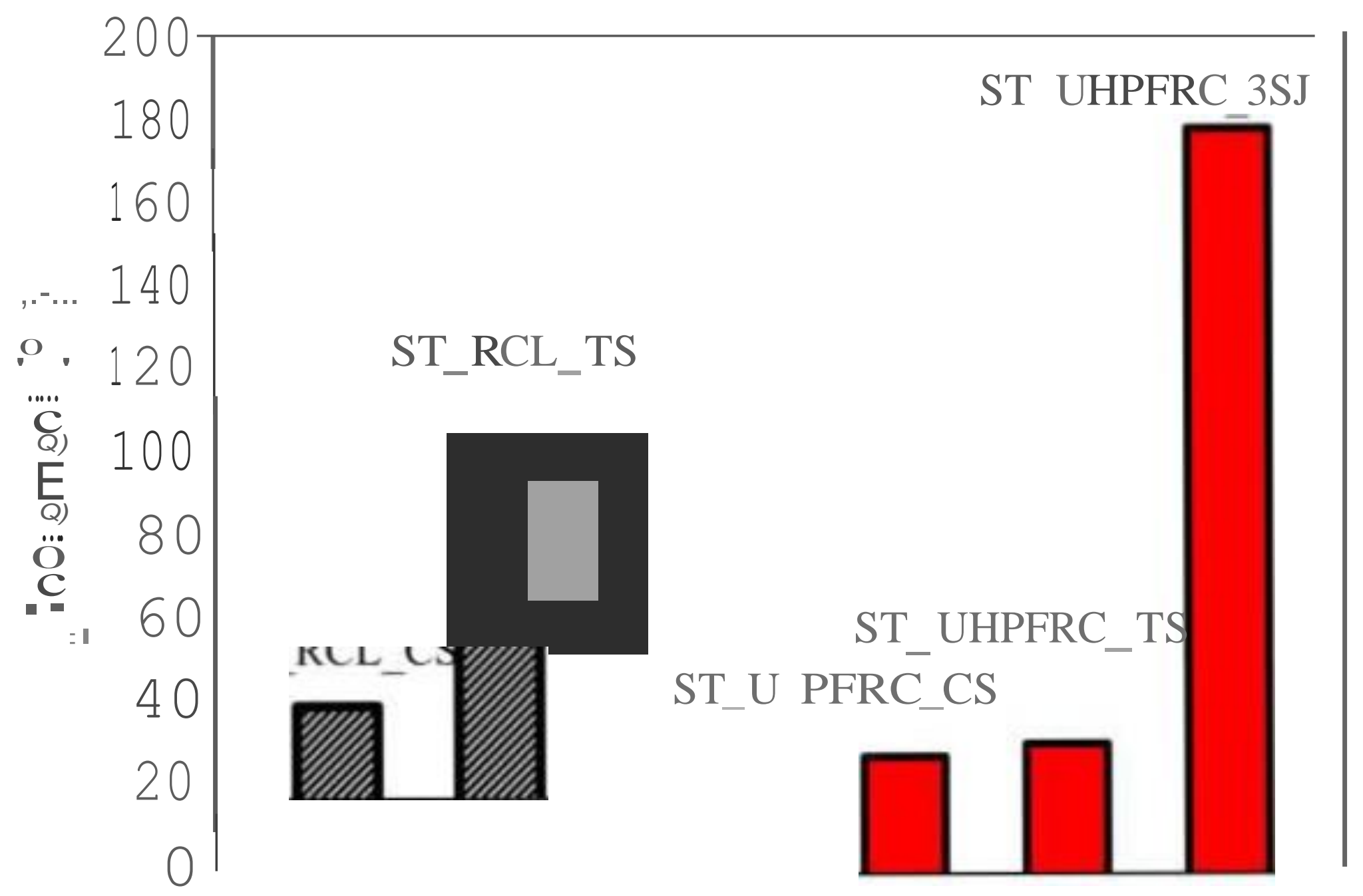






